\title{
Investigating the internal structure of the Antarctic ice sheet: the utility of isochrones for spatiotemporal ice-sheet model calibration
}

\author{
Johannes Sutter ${ }^{1}$, Hubertus Fischer ${ }^{1}$, and Olaf Eisen ${ }^{2,3}$ \\ ${ }^{1}$ Climate and Environmental Physics, Physics Institute and Oeschger Centre for Climate Change Research, University of \\ Bern, Bern, Switzerland \\ ${ }^{2}$ Helmholtz Centre for Polar and Marine Research, Alfred Wegener Institute, Bremerhaven, Germany \\ ${ }^{3}$ Department of Geosciences, University of Bremen, Bremen, Germany
}

Correspondence: Johannes Sutter (johannes.sutter@climate.unibe.ch)

Received: 26 November 2020 - Discussion started: 2 December 2020

Revised: 24 June 2021 - Accepted: 3 July 2021 - Published: 18 August 2021

\begin{abstract}
Ice-sheet models are a powerful tool to project the evolution of the Greenland and Antarctic ice sheets and thus their future contribution to global sea-level changes. Testing the ability of ice-sheet models to reproduce the ongoing and past evolution of the ice cover in Greenland and Antarctica is a fundamental part of every modelling effort. However, benchmarking ice-sheet model results against real-world observations is a non-trivial process as observational data come with spatiotemporal gaps in coverage. Here, we present a new approach to assess the accuracy of ice-sheet models which makes use of the internal layering of the Antarctic ice sheet. We calculate isochrone elevations from simulated Antarctic geometries and velocities via passive Lagrangian tracers, highlighting that a good fit of the model to twodimensional datasets such as surface velocity and ice thickness does not guarantee a good match against the 3D architecture of the ice sheet and thus correct evolution over time. We show that palaeoclimate forcing schemes derived from ice-core records and climate models commonly used to drive ice-sheet models work well to constrain the 3D structure of ice flow and age in the interior of the East Antarctic ice sheet and especially along ice divides but fail towards the ice-sheet margin. The comparison to isochronal horizons attempted here reveals that simple heuristics of basal drag can lead to an overestimation of the vertical interior ice-sheet flow especially over subglacial basins. Our model observation intercomparison approach opens a new avenue for the improvement and tuning of current ice-sheet models via a more rigid constraint on model parameterisations and climate forcing,
\end{abstract}

which will benefit model-based estimates of future and past ice-sheet changes.

\section{Introduction}

A core motivation of the ice-sheet modelling community is to provide meaningful projections of future sea-level rise. Towards this goal, great strides have been made in improving ice-sheet models (ISMs) to capture current and past modes of ice-sheet dynamics (Pattyn, 2018). However, at this point projections of the future behaviour of the Greenland and Antarctic ice sheets under global warming are divergent depending on model physics, initialisation and the choice of climate forcing (Seroussi et al., 2019, 2020; Goelzer et al., 2020). This has important ramifications for model-based estimates of future sea-level change (e.g. Edwards et al., 2021), especially in the case of the Antarctic ice sheet due to its potentially highly nonlinear response to climate warming (e.g. Garbe et al., 2020). Despite major improvements, ISM simulations today are constrained by incomplete boundary conditions such as uncertainties in the bedrock relief and geothermal heat flux; fragmental information of past and present climate conditions (especially with regard to ocean circulation underneath ice shelves); and model heuristics such as parameterisations of grounding-line dynamics, ice flow and iceshelf calving processes. To overcome these limitations, ISMs are usually tuned to observations of the past and present state of an ice sheet. Well-established two-dimensional data benchmarks used in ice-sheet modelling are, for example, the 
Bedmap2 (Fretwell et al., 2013), BedMachine (Morlighem et al., 2017, 2020) and MEaSUREs (Joughin et al., 2015, updated 2018; Mouginot et al., 2017) datasets for Antarctica and Greenland, which provide a continental coverage of bed topography, present-day ice-sheet geometry and surface flow. Such benchmarks are necessary to accurately reproduce the currently observed geometry and velocity. Ideally, ISMs are tuned not only to the present state of an ice sheet but also to palaeo-horizons to ensure their capability of capturing an ice sheet's evolution under climate conditions differing from the common era (e.g. DeConto and Pollard, 2016; Sutter et al., 2019; Seroussi et al., 2019; Edwards et al., 2019). Typical target climate epochs are the Last Glacial Maximum (LGM) and the Last Interglacial (LIG). Relatively well-constrained LGM grounding-line margins in Antarctica (Bentley et al., 2014) and palaeo-ice-sheet elevation proxies can be utilised as a tuning target (e.g. Albrecht et al., 2020). Sea-level reconstructions from the LIG can give an indication of ice loss in Antarctica and Greenland (Dutton et al., 2015). However, lack of spatial datasets for past climate states as well as uncertainties and sparse coverage of palaeo-proxy-based icesheet and sea-level reconstructions complicates the validation of palaeo-ice-sheet simulations.

Using the above-mentioned tuning targets allows for simulation of an ice sheet in line with the present-day observed surface properties and proxy data from the past millennia. However, the notion that a good fit to spatial datasets of the common era and proxy targets in the past guarantees the model's ability to respond accurately to future climate changes is debatable. Due to the complexity of ice sheetclimate interactions it is still challenging to create a proper initial ice-sheet configuration from which its future evolution can be adequately simulated (Seroussi et al., 2019, 2020). For example, tuning the ice sheet to the observed present state (e.g. via inversion for basal drag) by matching the current ice-sheet topography and surface flow does not guarantee the accurate reproduction of, for example, internal flow, ice temperature distribution and basal friction. It also could lead to overfitting of parameters relevant to ice flow within the scope of uncertain boundary conditions such as geothermal heat flux, sub-shelf ocean temperatures and surface mass balance. Without inversion the modelled present-day topography can differ from the observed state by several hundred metres of ice thickness, on the basis of which it is difficult to interpret model-based sea-level projections. Fundamentally, every ISM application is an ill-posed problem with non-unique solutions. Therefore, overfitting to a set of observables could lead to an initial ice-sheet configuration dominating the projected response to the applied climate forcing (Seroussi et al., 2019), especially over decadal to centennial timescales. Discrepancies in the initial state with respect to the actual realworld ice sheet can propagate and multiply during the model simulation due to the intrinsic nonlinearities of the system. Even a near-perfect match to present-day observables can conceal overfitting of the model due to weakly constrained boundary conditions, e.g. uncertainties in the climate forcing or geothermal heat flux (Burton-Johnson et al., 2020; Talalay et al., 2020). To counter the effects of overfitting, promising attempts to improve the initialisation of ice-sheet models have been made which involve transient inversions of multiple surface elevation observations over time (Goldberg et al., 2015), albeit only on the regional scale and limited to the extent of the satellite record. To reduce the effect of these limitations, we propose an additional data benchmark for ISMs which provides spatiotemporal constraints incorporating the palaeo-evolution of an ice sheet and complements the 2D and 1D tuning targets used hitherto.

Palaeo-surfaces within ice sheets are created by simultaneous deposition of impurities at the ice sheet's surface. These are widely observable by radio-echo sounding. The internal horizons (isochrones) of ice sheets provide a spatiotemporal calibration target for ISMs as they are formed by the threedimensional ice-flow patterns affected by bedrock undulations, geothermal heat flux and the palaeoclimate and therefore integrate all aspects of an ice sheet's evolution in one observable. Isochrones are mapped by radar observations as individual radar reflections within the ice and are subsequently dated, for example, by using tie points to ice-core chronologies (crossover points) or distinct reflectors such as dated volcanic eruptions. An ice-sheet-wide coverage of such traced and dated englacial layers, as envisioned by the SCAR action group AntArchitecture (Bingham, 2020), would be an invaluable tuning benchmark, which constrains both the climate forcing and the simulated ice flow more tightly than the usually employed $2 \mathrm{D}$ or 1D data targets. So far, isochrones have been used in or with ice-flow models (1D, 2D or 3D) to reconstruct palaeo-accumulation patterns and their changes, e.g. in Waddington et al. (2007), Leysinger Vieli et al. (2011), Karlsson et al. (2014) and Cavitte et al. (2018), or to constrain high-resolution alpine glacier models (Konrad et al., 2013; Jouvet et al., 2020). Specialised models have been developed to compute isochrone geometry (Hindmarsh et al., 2009) or are tailor-made to accurately simulate the internal layering of ice sheets (Born, 2017). Lagrangian and semiLagrangian tracer advection has been employed to shed light on the isotopic composition and stratigraphies of the Greenland and Antarctic ice sheets (Clarke et al., 2003, 2005; Lhomme et al., 2005a, b; Huybrechts et al., 2007; Goelles et al., 2014; Born, 2017), to identify potential locations of old ice in Antarctica (Passalacqua et al., 2018), and recently to assess past ice-sheet instabilities (Sutter et al., 2020). Despite these achievements, englacial isochrones have not been getting the required attention in the context of tuning targets for continental ISMs (Born, 2017).

In this work, we discuss the ability and limitations of a 3D continental ISM to capture englacial layers and therefore to exploit existing isochrone elevation datasets to constrain ISM results. We compare model results to dated isochrones spanning a large part of the East Antarctic ice sheet and discuss how such a comparison can be utilised to improve 
Table 1. Overview of analysed isochrones. Transects presented in this work are DC-X45a, X57a, Y77a, Y90a, CEA-10 and DML VIII23/IV-24 (in bold).

\begin{tabular}{|c|c|c|c|}
\hline Name & Region & $\begin{array}{r}\text { Line } \\
\text { length }(\mathrm{km})\end{array}$ & Age (ka) \\
\hline DC - X45a, X57a, Y77a, Y90a ${ }^{C}$ & Dome C & 100 & $38,48,73,96,130,160$ \\
\hline $\mathrm{CEA}-7,8, \mathbf{1 0}, 12,13^{\mathrm{W}}$ & Wilkes Basin - Dome C - Vostok - Dome A & $400-1800$ & $38,90,161$ \\
\hline DML - II-04, II-08, IV-24, VIII-22, VIII-23W & Dome Fuji - EDML & $200-800$ & 38,74 \\
\hline $\mathrm{DC}-1,2,3^{\mathrm{LV}}$ & Dome C & $50-600$ & $36.5,73,130,170$ \\
\hline $\mathrm{V}-1,2,2 \mathrm{~W}, 3^{\mathrm{LV}}$ & Vostok - Dome A - South Pole & $50-2000$ & $36.5,73,130,170$ \\
\hline B & Titan Dome & $\approx 100 \mathrm{~km}$ & $4.7,10.7,16.8,29,37.6,51.4,72.5$ \\
\hline A & Weddell Sea sector West Antarctica & $\approx 100-600 \mathrm{~km}$ & $3.1,5.6,6.4$ \\
\hline
\end{tabular}

Isochrones are from Cavitte et al. (2016, 2020) ( ${ }^{\mathrm{C}}$ DC - X45a, X57a, Y77a, Y90a), Winter et al. (2019) ( ${ }^{\mathrm{W}}$ CEA-7, 8, 10, 12, 13, DML - II-04, II-08, IV-24, VIII-22, VIII-23), Leysinger Vieli et al. (2011) ( $\left.{ }^{\mathrm{LV}} \mathrm{DC}-1,2,3, \mathrm{LV} \mathrm{V}-1,2,2 \mathrm{~W}, 3\right)$, Beem et al. (2020) and Ashmore et al. (2020). The superscripts (C, W, LV, B, A) denote the respective publication (C: Cavitte et al., 2016, 2020; W: Winter et al., 2019; LV: Leysinger Vieli et al., 2011; B: Beem et al., 2020; A: Ashmore et al., 2020). The line lengths $(x-y)$ specified in the table vary depending on the transect except for the data from Cavitte et al. $(2016,2020)$, where all transects are $100 \mathrm{~km}$ in length. The specified ages are those used in this paper but do not represent the complete set of internal layers available in the respective references. The transects shown in the lower half of the table are not discussed in this work.

ISM simulations. Thus, this work does not aim to reconstruct the internal architecture of the Antarctic ice sheet in as detailed a way as possible (as e.g. done locally in Parrenin et al., 2017) but rather to exploit isochrones as a constraint on model behaviour to improve the modelling of palaeo-icesheet evolution. In Sect. 2 we introduce the post-processing routine (Lagrangian tracer advection) and the input data, give an overview of the observed traced and dated internal layers from East Antarctic radar transects discussed in this study, and summarise the ice-sheet model setting. In Sect. 3 we focus on the ice-core deep drilling site Dome $\mathrm{C}$ and provide a detailed analysis of the simulated internal layering in comparison to a set of observed layers from four individual radar transects, discussing palaeo-accumulation patterns and the impact of ice dynamics as well as uncertainties in bedrock elevation and geothermal heat flux. Finally, we expand this view to the whole East Antarctic ice sheet in Sect. 4, where we highlight regions where our model-isochrone comparison shows systematic deficits in the modelled ice flow and suggest processes and parameterisations in the model that may be responsible for these deficits.

\section{Approach to modelling Antarctic isochrones}

We use ISM results from Sutter et al. (2019) as well as a new set of palaeo-simulations and a present-day equilibrium ensemble obtained from simulations with the Parallel Ice Sheet Model (PISM) (The PISM authors, 2021; Bueler and Brown, 2009; Winkelmann et al., 2011) to compute Antarctic isochrone elevations. We tune the ISM to match observational data from present day (PD), the Last Glacial Maximum (LGM) and the Last Interglacial (LIG). Tuning targets include the surface elevation at East Antarctic ice-core locales as well as the grounding-line extent at the LGM (Bentley et al., 2014), LIG sea-level reconstructions (Dutton et al., 2015), and PD sea-level-equivalent ice volume and grounding-line position (Fretwell et al., 2013). We choose selections of traced and dated englacial layers that have crossovers with the EPICA Dome C (EDC), EPICA Dronning Maud Land (EDML), Dome Fuji and Vostok ice cores. Unfortunately, the number of published and available traced and dated Antarctic isochrones is limited at the current stage, a situation which initiatives like AntArchitecture aspire to improve in the coming years. For this intercomparison we make use of three compilations of dated isochrones (Leysinger Vieli et al., 2011; Cavitte et al., 2016, 2020; Winter et al., 2019), which provide about $10000 \mathrm{~km}$ of analysed radar transects with dated isochrones covering the past 38 to $170 \mathrm{kyr}$ BP (see Table 1). We focus on this time period as dated isochrones from this range are available for all regions considered here. Both younger and older dated isochrones are available, for example, for Dome C, Titan Dome (Beem et al., 2020) and for West Antarctica (Ashmore et al., 2020) (see Table 1). With this wealth of information we are able to analyse the performance of our model simulations not only close to ice-core locations but also along and across ice divides, spanning the whole distance from Dronning Maud Land to the George V Coast (see Fig. 1). The area connected by the radar transects covers a wide range in the spectrum of bedrock relief and geothermal heat flux as well as climate regimes and ice-sheet elevations. This allows us to analyse the impact of uncertainties in the palaeo-mass balance, basal melt, ice dynamics and bedrock on modelled isochrone elevations. Table 1 gives an overview of the radar transects analysed in this work. The Dome $\mathrm{C}$ region is included in Leysinger Vieli et al. (2011), Winter et al. (2019) and Cavitte et al. (2020) and provides an excellent test bed for the validity of the climate forcing scheme employed by Sutter et al. (2019). The EDC ice core provides tight constraints on the age of the isochrones via the AICC2012 chronology (Veres et al., 2013; Bazin et al., 2013) as well as the accumulation history during the last glacial-interglacial cycle (Cavitte et al., 2018). It is important to note that, as the ISM's climate forcing was modulated via the EDC deuterium record, we expect the best fit of our computed isochrones to be in the 


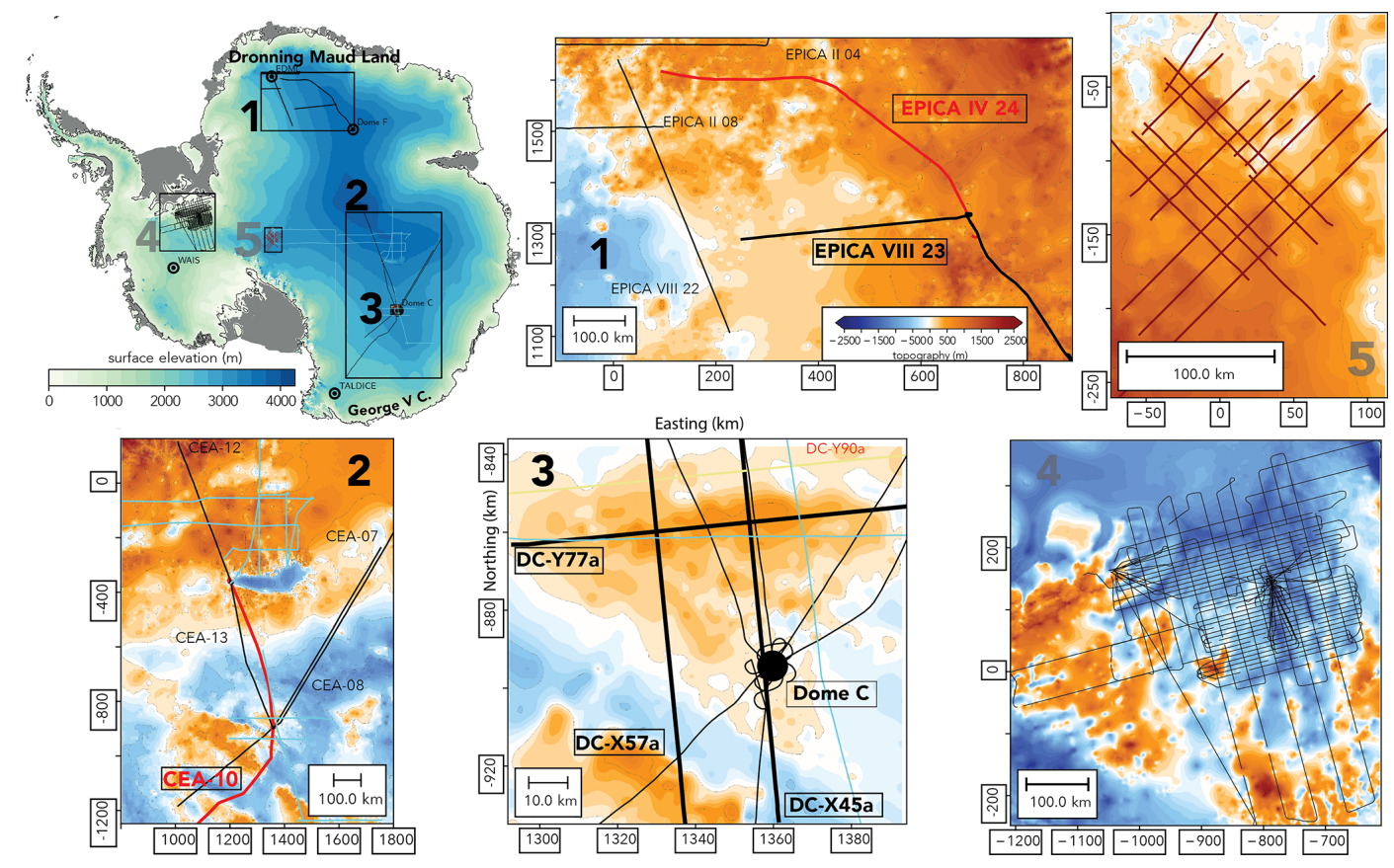

Figure 1. Antarctic surface (top left) and bedrock elevation from BedMachine Antarctica (Morlighem et al., 2020) overlain by radar transects with individual dated isochrones analysed in this study. The enlarged sections highlight regional clusters and their respective topographic settings. Clusters 1-3 are discussed in this study. The isochrone data are from cluster (1) - Winter et al. (2019); cluster (2) and (3) Leysinger Vieli et al. (2011), Cavitte et al. (2016), Cavitte et al. (2020) and Winter et al. (2019); cluster (4) - Beem et al. (2020); and cluster (5) - Ashmore et al. (2020). Northing and easting are attained via cartographic transformation based on the WGS84 reference coordinate system.

region encompassing this ice core. The areas around EDC, Dome Fuji and EDML are all well sampled by reliable radar observations, therefore providing very accurate estimates of bedrock elevation (Karlsson et al., 2018). This makes it possible to investigate the impact of bedrock uncertainties on the mismatch between observed and computed isochrone elevations. Finally, the transects in the vicinity to faster-flowing marine drainage regions (e.g. Wilkes Subglacial Basin) allow for an assessment of model parameterisations of ice flow on the computed isochrone elevation.

\subsection{Observation of isochrones}

Radar surveys of ice sheets observe numerous internal layers, i.e. changes in the dielectric properties of the ice, which lead to a partial reflection of the downward-propagating radar wave back to the surface. Most of these layers are caused by changes in the conductivity content of the ice by deposition of acids from volcanic eruptions at the surface of the ice sheet. After volcanic eruptions these depositions usually occur over a few years and are rather homogeneous over spatial scales of tens to hundreds of kilometres. The absence of melting on the Antarctic plateau leads to continuous burial and, thus, submergence of these conductivity layers, which are typically spread over less than $1 \mathrm{~m}$ (Eisen et al., 2006). Lateral variations in accumulation rates cause differences in submergence velocities and, thus, lead to deformation of these initially surface-parallel layers. With increasing depth, the influence of ice dynamics on the (vertical) submergence velocity increases and deforms the layers further.

Radar systems used to map internal layers and the thickness of ice sheets operate in the range of tens to hundreds of megahertz, corresponding to wavelengths on the order of metres. The width of the observed reflections, caused by the interaction of the electromagnetic radar waves with the conductivity peaks, is determined by the bandwidth or pulse length of the radar systems. They are typically in the range of $0.5 \mathrm{~m}$ to several tens of metres (Winter et al., 2017).

Occurrences of basal melt, e.g. due to high local geothermal heat flux, can cause deformation of the internal layers closer to the bed. With increasing depth the internal layers follow the bed topography in an often smoothed fashion. Thus, the lateral variation in the depth of these internal reflection horizons is usually sufficiently small to be continuously detected with the spatial sampling distance of airborne radar systems. They operate with a horizontal sampling distance in the range of metres to tens of metres (Winter et al., 2017) and can be traced over hundreds to thousands of kilometres. As each of these layers originates from the same physical change in conductivity, which the ice inherited during deposition as snow at the surface, they are considered isochrones and have the same age along the reflection horizon. 


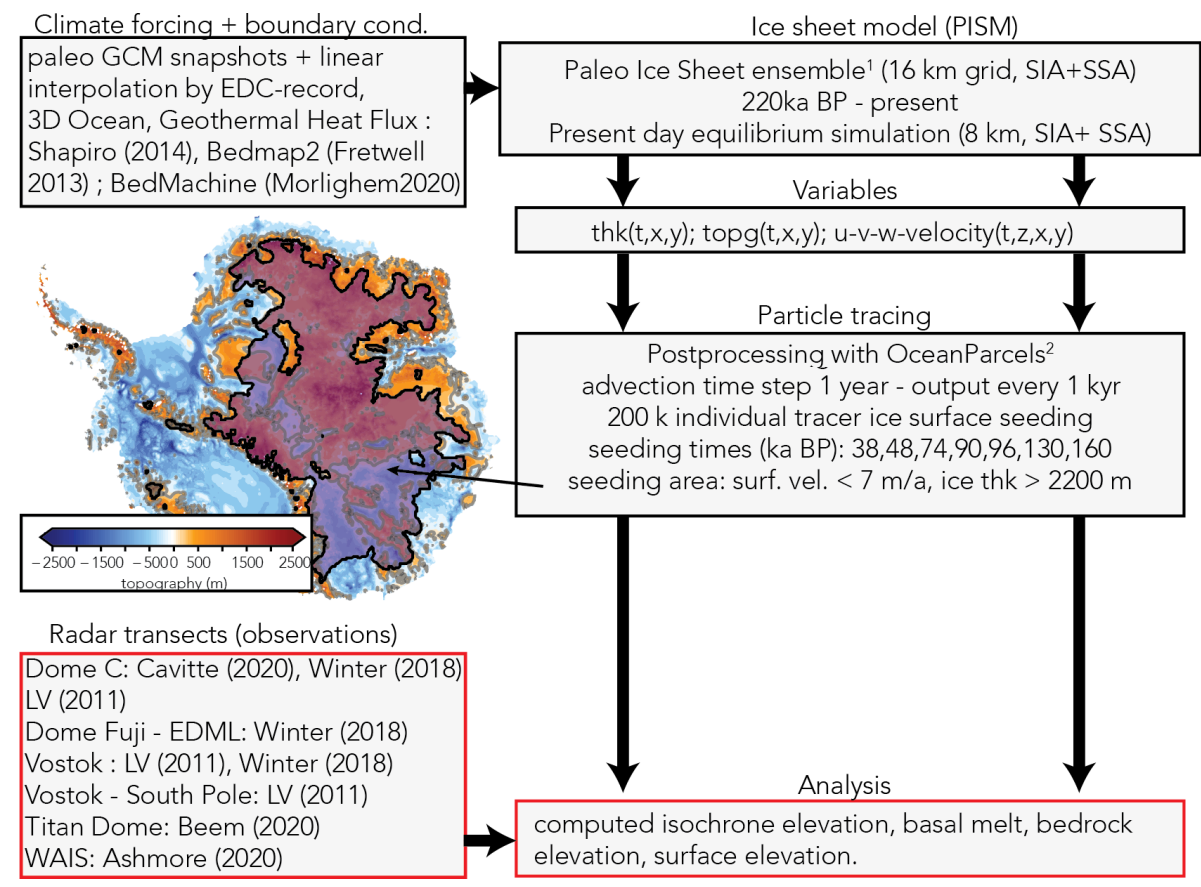

Figure 2. Experimental set-up. The left column depicts the input data to the ISM (climate forcing, geothermal heat flux and initial geometry) and to the data intercomparison (observed radar transects). The contour plot illustrates the area where tracers are seeded (see Video supplement). The right column contains the ISM specifications, required variables (thickness, bedrock topography and 3D velocity field) for the tracing scheme and the settings used in OceanParcels (Lange and van Sebille, 2017).

Dating can most reliably be achieved by tying internal layers to ice-core sites, where age-depth estimates are available from ice-core proxy analysis. For the comparison of observed and modelled isochrone elevations, the uncertainty in the observed isochrones is an important parameter. Apart from the radar-inherent uncertainties associated with identifying and continuously tracing the same radar signal for a horizon and the conversion of two-way travel time to depth, the uncertainty in the ice-core ages and the actual matching procedure between horizons and ice core are the largest sources of error.

We use various internal layers in this study. Details on the radar resolution, dating methods and resulting uncertainty can be found in the respective original publications (Cavitte et al., 2016; Winter et al., 2019; Cavitte et al., 2020; Leysinger Vieli et al., 2011). Based on the analysis performed on five different radar systems by Winter et al. (2017) near EDC, we consider a maximum age uncertainty of around $1 \mathrm{ka}$ for each isochrone above $2000 \mathrm{~m}$ depth (roughly $2 / 3$ of the ice thickness) (Winter et al., 2019). This range covers most of the horizons considered in this study. Below a depth of $2000 \mathrm{~m}$, the age uncertainty increases nonlinearly with depth towards the bed (Winter et al., 2019). At places where the deepest ice is younger than the ice around Dome $\mathrm{C}$, the age gradient with depth will then be less steep towards the bed than the one determined at Dome $\mathrm{C}$. Thus, the age uncertainties in the horizons below $2000 \mathrm{~m}$ depth will be lower than at Dome C. We consider this uncertainty always to be smaller than the proposed age derived from the ISM data.

\subsection{Large-scale ice-sheet modelling}

In order to compute Antarctic isochrones, time-resolved 3D velocity data as well as the transient ice-sheet geometry (ice thickness and bedrock topography) are necessary. We therefore ran a palaeoclimate model ensemble covering the last $220 \mathrm{kyr}$. All $220 \mathrm{kyr}$ simulations were initialised from the $220 \mathrm{kyr}$ output of a $2 \mathrm{Myr}$ long simulation in Sutter et al. (2019). We also make use of four simulations from Sutter et al. (2019) which are based on four different geothermal heat flux fields (Shapiro and Ritzwoller, 2004; Purucker, 2013; An et al., 2015; Martos et al., 2017). In addition to the $220 \mathrm{kyr}$ palaeo-ensemble, we carried out a present-day equilibrium ensemble to assess the impact of the missing palaeospin-up as well as different model parameterisations on the computed isochrone elevations.

Isochrone elevations (see Sect. 2.3) are computed on the basis of (1) full palaeo-ISM runs (called pal), in which model integration starts from the $220 \mathrm{kyr}$ time slice of a $2 \mathrm{Myr}$ simulation (Sutter et al., 2019); (2) the present-day snapshot of the $220 \mathrm{kyr}$ simulation (pd-pal); and (3) a present-day equilibrium ensemble (pd) with an integration time of 2000 years following a thermal spin-up using a fixed ice-sheet geometry for 200 kyr. The 2 Myr simulations in Sutter et al. (2019) are initialised at $2 \mathrm{Ma}$ from a present-day ice-sheet geometry. 
Isochrone evolution starts at the isochrone's respective age (see Table 1) in the past and follows the computed transient ice flow. In the present-day snapshot (pd-pal) and present-day equilibrium ensemble (pd), isochrones evolve on the basis of the simulated present-day flow (constant velocity field).

The climate forcing for the present-day ensemble was derived from the regional climate model Regional Atmospheric Climate Model (RACMO) (van Wessem et al., 2014) and the World Ocean Atlas 2018 (Locarnini et al., 2019). The parameter range chosen for the PD ensemble is associated with an equilibrium sea-level-equivalent ice volume within $\pm 2 \mathrm{~m}$ of present-day observations (Fretwell et al., 2013). Both the palaeo-simulations and the present-day equilibrium simulations were tuned to match the observed present-day surface elevation (with a focus on the deep-ice-core sites), ice volume and grounding-line position. An overview of the experimental set-up is provided in Fig. 2. The model forcing used in the palaeo-simulations is described in detail in Sutter et al. (2019) and provides spatiotemporal information on ocean temperatures, surface temperature and precipitation derived from climate snapshots during the LIG (Pfeiffer and Lohmann, 2016) and the LGM as anomaly forcing with respect to the modelled pre-industrial climate state. In between the climate snapshots, surface temperature and ocean temperatures are interpolated on the basis of the EDC deuterium data (Jouzel et al., 2007) using a temperature-precipitation relationship of $3 \% \mathrm{~K}^{-1}$ (see Sect. 2.3 and Fig. 2 in Sutter et al., 2019) and $5 \%, 6 \%$ and $8 \% \mathrm{~K}^{-1}$ for the $220 \mathrm{kyr}$ simulations. The ISM is run on a $16 \mathrm{~km}$ grid with 81 vertical levels. Bedrock elevation changes due to transient load changes are computed via the Lingle-Clark model based on Lingle and Clark (1985) and Bueler et al. (2007). We employ a combination of the shallow-ice approximation (SIA) and shallow-shelf approximation (SSA) (SSA-SIA hybrid; Winkelmann et al., 2011) with a sub-grid grounding-line parameterisation (Gladstone et al., 2010; Feldmann et al., 2014) to allow for reversible grounding-line migration despite using a relatively coarse resolution (Feldmann et al., 2014). Table 2 provides an overview of the friction and sliding parameters chosen for the $2 \mathrm{Myr}, 220 \mathrm{kyr}$ and present-day model ensemble. In PISM the till friction angle $\phi$ controls the yield stress at the ice-bedrock interface, which can be set to be a function of the bedrock elevation (increasing with elevation). The yield stress is determined by

$\tau_{c}=\tan \phi N_{\mathrm{till}}$,

where $\phi$ is the bedrock-elevation-dependent till friction angle and $N_{\text {till }}$ the effective pressure. As in Sutter et al. (2019) we choose a pseudo-plastic power law with the parameter $q$ controlling the amount of sliding via the relationship

$\tau_{b}=-\tau_{c} \frac{\boldsymbol{u}}{u_{\text {threshold }}^{q}|\boldsymbol{u}|^{1-q}}$,

where $\tau_{b}$ is the shear stress, $\boldsymbol{u}$ ice velocity and $u_{\text {threshold }}$ the threshold velocity at which $\tau_{b}$ has the exact magnitude as
Table 2. Overview of parameters relevant for sliding in Sutter et al. (2019) (2 Ma), for the $220 \mathrm{kyr}$ ensemble $(220 \mathrm{k})$ and for the presentday ensemble (PD); $\phi_{1}$ is the minimum (for depths below $-700 \mathrm{~m}$ ) and $\phi_{2}$ the maximum (for depths above $0 \mathrm{~m}$ ) till friction angle.

\begin{tabular}{lrrrr}
\hline Parameter & $\phi_{1}$ & $\phi_{2}$ & $\mathrm{q}$ & $\mathrm{sia}_{e}$ \\
\hline $2 \mathrm{Ma}$ & 5 & 30 & 0.6 & 1.0 \\
$220 \mathrm{k}$ & 5 & 30 & 0.6 & 1.0 \\
$\mathrm{PD}$ & $2,3,4,5$ & 30 & $0.6,0.75$ & 1.0 \\
\hline
\end{tabular}

$\tau_{c}$ (condition for sliding). The so-called SIA enhancement factor in the $220 \mathrm{kyr}$ and present-day ensemble is 1.0 as in Sutter et al. (2019). For further details regarding the ISM setup see Sect. 2.1 in Sutter et al. (2019).

Geothermal heat flux is taken from Shapiro and Ritzwoller (2004) or alternatively from Purucker (2013), An et al. (2015) and Martos et al. (2017). Surface and bedrock elevation data are from Bedmap2 (Fretwell et al., 2013), except in the present-day simulation, where we use the new BedMachine-Antarctica dataset from Morlighem et al. (2020).

\subsection{Lagrangian tracer advection}

We use the open-source Python software OceanParcels v0.9 (Lange and van Sebille, 2017), which was originally designed to analyse ocean data but can be easily adopted for transient or steady-state ISM data. At its core, OceanParcels provides a Lagrangian particle tracking scheme which is computationally efficient and adaptable to a variety of input grids (Delandmeter and van Sebille, 2019). Individual particle tracks are computed following the advection equation (Eq. 1 in Lange and van Sebille, 2017):

$\mathbf{X}(t+\Delta t)=\mathbf{X}(t)+\int_{t}^{t+\Delta t} \mathbf{v}(\mathbf{x}, \tau) \mathrm{d} \tau+\Delta \mathbf{X}_{b}(t)$,

where $\mathbf{X}$ is position of the particle in space; $\mathbf{v}$ is the threedimensional velocity at the particles' position; and $\Delta \mathbf{X}_{b}(\tau)$ is the change in position due to "behaviour", which does not play a role in our application as we assume that every ice parcel is passively advected with the velocity field without any additional advection terms. For further details regarding OceanParcels please refer to Lange and van Sebille (2017). For OceanParcels to work we need to provide threedimensional velocity data covering the time frame we are interested in (i.e. the last $160 \mathrm{kyr}$ as this is the age of the oldest isochrone we take into account) as well as the ice sheet's geometry (thickness and bedrock elevation) at sufficiently high temporal resolution. Naturally, the finer the temporal resolution of the ice-sheet time slice data, the more accurate the particle tracks will be. However, to prevent input data for OceanParcels from getting too large for standard Python libraries (numpy, scipy, netCDF4) and memory, we opted for 
a temporal resolution of 1 and $10 \mathrm{kyr}$, which proved to be accurate enough (small deviations compared to the model uncertainties with respect to observations) for the mostly relatively slow ice flow in East Antarctica. Velocity snapshots between 1 and $10 \mathrm{ka}$ largely produce the same isochrone elevation (see Fig. 3). We set the advection time step $(\Delta t)$ to 1 year, and for each experiment we deploy 200000 individual tracers, which we seed at the ice surface at the time of the age of the isochrone we want to compute (e.g. at $38 \mathrm{ka}$ for the $38 \mathrm{ka}$ isochrone). Misfits of the model results in terms of elevation and velocity field relative to the true (unknown) ice-sheet state at that point in time in the past and throughout the palaeo-simulation will lead to deviations in the modelled isochrone as observed in the ice sheet today. This information can then be used to identify such misfits and improve the model representation of the ice sheet. Here, it is important to note that observed isochrone elevations are usually defined as relative to the ice surface whereas we compute the isochrone elevation above the ice bed. Any deviations in the modelled ice bed with respect to observations will therefore be imprinted on the modelled isochrone elevation. Therefore, any comparison between modelled and observed isochrone elevations will be most meaningful along transects with small deviations between the observed and modelled bedrock elevation. We find that for less than $10^{5}$ tracers, gaps in coverage due to the dispersive nature of ice flow are too large to resolve the internal layers away from ice divides. Figure 3 illustrates the changes in the computed isochrone elevation due to different numbers of deployed tracers. In regions where homogenous flow dominates (see transect depicted in Fig. 3a), the number of tracers does not affect the simulated isochrone elevation much. However, if spatial gradients in ice-flow increase, simulated isochrone elevations diverge with low tracer densities. This is shown along kilometres 400-200 in Fig. 3b, where elevated surface velocities closer to the coast lead to more pronounced deviations in simulated isochrone elevations for a coarse seeding strategy.

The seeding mask (i.e. the region where tracers are initiated) consists of the area with an ice thickness of more than $2200 \mathrm{~m}$ and surface flow slower than $7 \mathrm{~m} \mathrm{a}^{-1}$ (see Fig. 2 and the Video supplement). The seeding mask covers an area which encloses every individual radar transect analysed here. We also tested other seeding strategies employing the ice sheet mass balance intercomparison exercise (IMBIE) drainage basins (Zwally et al., 2012) and ice divides or around ice-core locations. The choice of seeding mask is solely motivated by the tracer coverage. As long as the transects of interest are covered by the seeding mask, the latter only affects the density of tracers (a larger seeding mask leads to sparser tracer coverage if the number of tracers is not adjusted accordingly). We found that a seeding mask defined by the ice thickness and surface flow considerations mentioned above provides good coverage for the radar transects discussed in this study. The tracer experiments were all carried out on a laptop computer (Powerbook (2015), 2.7 GHz,
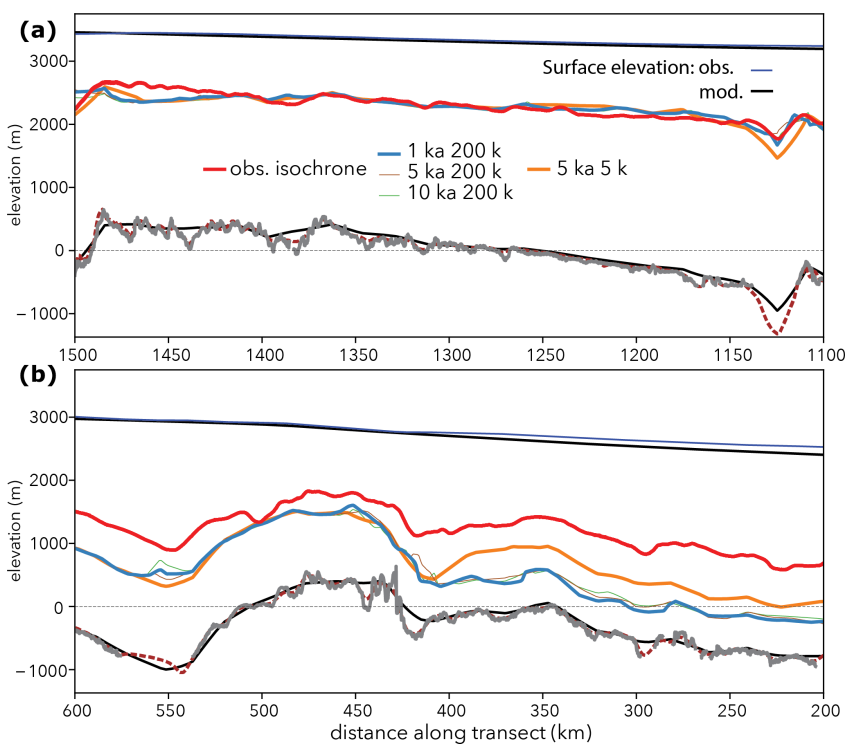

Figure 3. Observed and simulated isochrones along transect CEA10 (see Fig. 10 for the location of transect CEA-10). Observed isochrone is shown in red; simulated isochrones are computed based on snapshot velocity fields every 1,5 and $10 \mathrm{kyr}$. Tracer seeding was carried out with 200000 and 5000 tracers. Bedrock and surface elevation in the model runs is plotted in black, observed surface elevation in dark blue, and bedrock elevation derived from the radar transect in grey. The gridded $1 \mathrm{~km}$ BedMachine bedrock elevation (Morlighem et al., 2020) is plotted for comparison as well (smooth dashed red line).

8 GB memory, OS-X: 10.13.6), with computation times between a few hours (38 ka isochrone) and 10-15 h (160 ka isochrone), i.e. $\approx 1 \mathrm{~h}$ for every $10 \mathrm{kyr}$ elapsed model time. On a more recent machine (Powerbook (2020), $4 \times 2.3 \mathrm{GHz}$, 32 GB memory, OS-X: 11.3 ) this can be reduced to $\approx 10 \mathrm{~min}$ for every $10 \mathrm{kyr}$.

OceanParcels provides netCDF files consisting of the individual tracer positions in space and time. Accordingly, to extract isochrones we selected the last tracer positions and gridded them to a regular $1 \mathrm{~km} \times 1 \mathrm{~km}$ grid (bi-linear interpolation). This provided an elevation map of the respective tracer swarm for all regions covered by the seeding mask (see Fig. 4a and Video supplement). From this elevation map we then extracted the computed tracer elevation. From the ice-sheet model output we retrieved the bedrock and surface elevation, the melting at the base of the ice, and the corresponding geothermal heat flux (the latter being derived from the input data) along the individual radar transects. Our main goal is the identification of systematic mismatches between predicted and observed isochrone geometry. As a metric for the difference between observed and modelled isochrones we use their respective elevations in the ice sheet above the ice-bed interface, normalised by the local ice thickness. This yields the root mean square difference (RMSD) in per cent. 

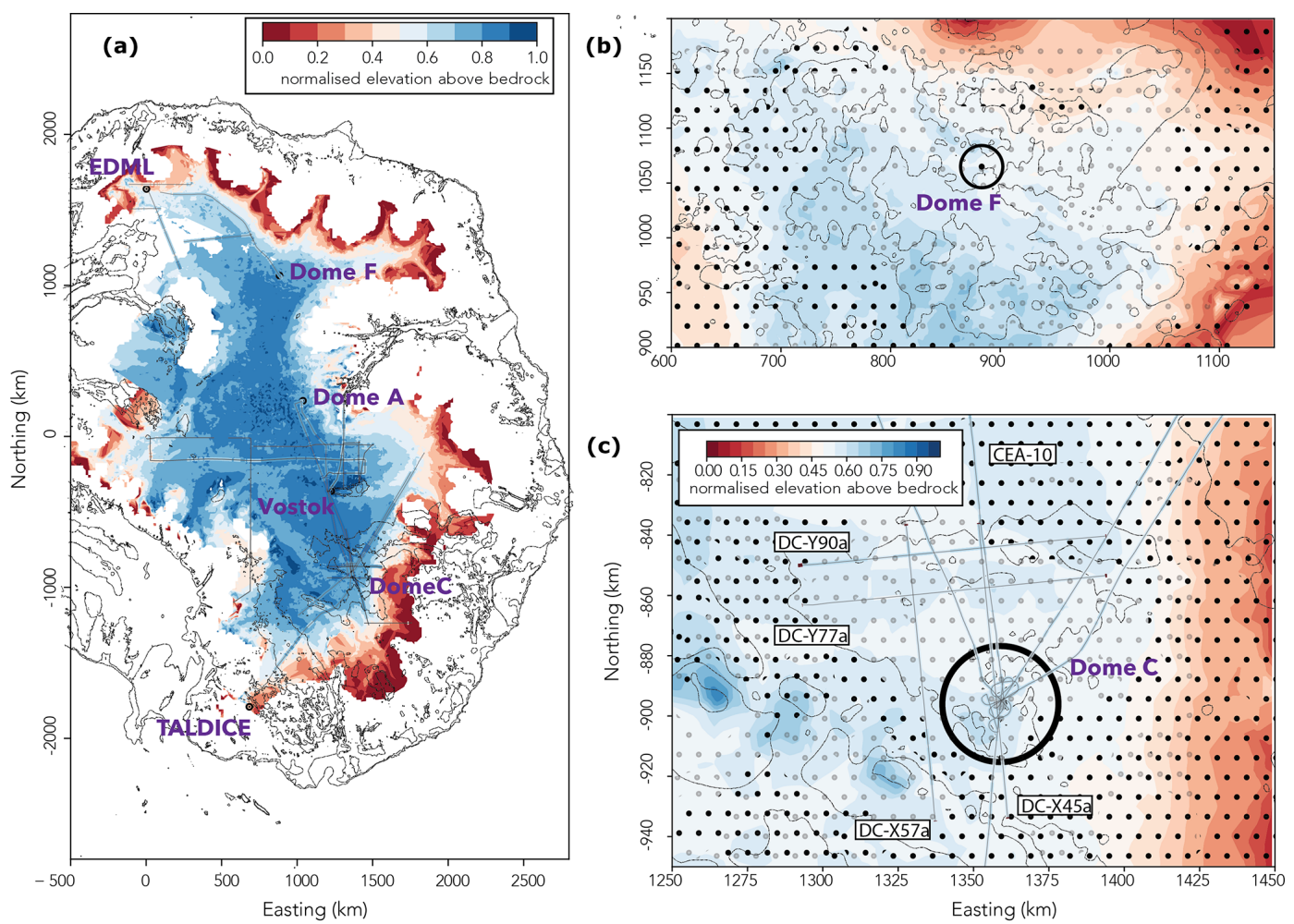

Figure 4. Computed isochrone elevation in East Antarctica. Panel (a) illustrates the elevation above bedrock of the 38 ka isochrone normalised by the local ice thickness. The filled isochrone contours are overlain by the normalised elevation of the observed isochrones (thin coloured lines). Black shapes in (a) depict the zero-metre sea-level bedrock contour. Panel (b) shows a magnification of the region around Dome Fuji with dotted areas (filled black circles) where basal melt is simulated. Semi-transparent dots show results with geothermal heat flux forcing from Martos et al. (2017) and opaque dots from Shapiro and Ritzwoller (2004), respectively. Panel (c) shows the area around Dome C overlain by the normalised elevation of the observed isochrones (thin coloured lines). The mismatch between the simulated isochronal layer and the observed isochrone elevation along the transects is generally small in the Dome $\mathrm{C}$ region with the exception of the upper right section in (c), where the simulated isochrone is off by up to $40 \%$ of the local ice thickness.

\section{Modelled Antarctic isochrone elevations}

Our main goal is the identification of systematic mismatches between predicted and observed isochrone geometry. To achieve this, we focus on three major sources of model observation mismatches: (i) climate forcing, (ii) model parameterisation, (iii) bedrock and geothermal heat flux. As computed isochrone elevations will be affected by a superposition of uncertainties from all three sources, we separate our analysis into regions where we expect only one factor to dominate. To isolate the effect of (i) climate forcing we turn to areas characterised by limited ice flow (e.g. ice domes or close to ice divides) and by a good representation of the bedrock elevation in the model (difference between input dataset and local high-resolution radar data). We primarily focus on Dome $\mathrm{C}$ as ice-sheet model parameters relevant for ice flow and basal friction were tuned to match the regional ice-sheet configuration. To gauge the impact of ice-flow parameterisation (ii) we assess the fit of modelled isochrones in regions of elevated surface velocities and in subglacial basins (bedrock below sea level) as well as the effect of different parameter choices (see Table 2) under the same boundary conditions (climate, geothermal heat flux, bedrock topography). To test (iii) we analyse the impact on bedrock elevation uncertainty around Dome $\mathrm{C}$ and use different geothermal heat flux fields to investigate their influence on the modelled internal layer architecture. We would like to note that while we simulate isochronal layers throughout East and West Antarctica, our model observation intercomparison is mostly limited to ice domes and along ice divides in East Antarctica as these regions are covered by dated radar-based isochrone observations. Future radar explorations in Antarctica will hopefully complement the available data by observations away from ice divides and along drainage sectors as these are the regions which point to critical misrepresentations in ice-sheet model simulations.

\subsection{Dome C - evaluating the palaeoclimate forcing (i)}

We now turn to the first (i) of the aforementioned three main factors determining simulated isochrone elevations, the cli- 

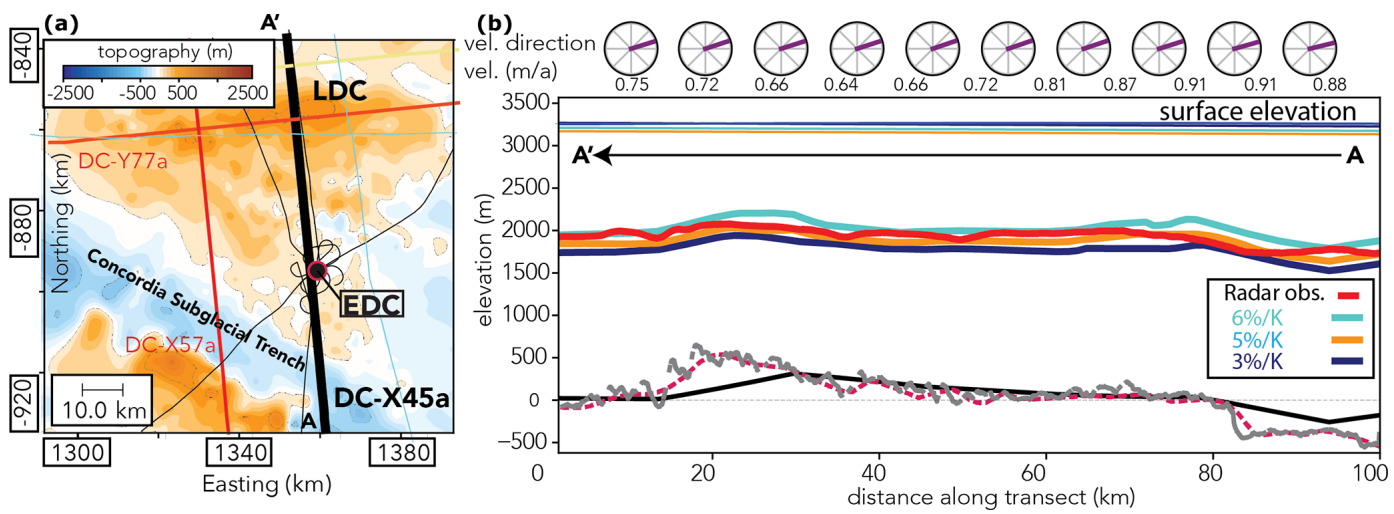

Figure 5. Transect DC-X45a with the $96 \mathrm{ka}$ isochrone. Panel (a) illustrates the bedrock elevation and radar transects analysed in this study crossing Dome C. In (b) the computed isochrone elevations for simulations with 3\%, $5 \%$ and $6 \%$ precipitation change per Kelvin surface temperature change are plotted against the observed isochrone (red line). The modelled surface elevation is plotted in the corresponding colour of the modelled isochrones, and the observed surface elevation (Fretwell et al., 2013) is depicted in dark blue. Bedrock elevation in the model is plotted in black and bedrock elevation derived from the radar transect in grey. The gridded 1 km BedMachine bedrock elevation (Morlighem et al., 2020) is plotted for comparison as well (smooth dashed red line). The circles on the top of (b) denote the relative flow direction and speed with respect to the radar transect.

mate forcing. Due to the near cessation of surface flow at ice domes the local internal stratigraphy is by and large dominated by the regional surface mass balance history and potentially affected by basal melting due to a large ice thickness, low surface accumulation and/or elevated geothermal heat flux. Consequently, in the particular geographical setting of an ice divide, we do not expect that parameterisations of ice dynamics will have a large effect on the internal layer architecture. Therefore, we assume that model mismatches with respect to observed isochrones are mostly due to the applied surface mass balance forcing and geothermal heat flux. To evaluate the validity of the forcing approach in Sutter et al. (2019) and in this work, we turn to several radar transects in the vicinity of the EDC ice core $\left(75^{\circ} 1^{\prime} \mathrm{S}, 123^{\circ} 4^{\prime} \mathrm{E}\right.$; see Fig. 5) which satisfy the condition of low ice surface velocities. It is important to note that the model parameters chosen in Sutter et al. (2019) were tuned using a climate forcing with a temperature-precipitation relationship of $3 \%$. The palaeosimulations created for this paper employ identical model parameters and the same forcing (see Sect. 2.2) but with alternative temperature-precipitation relationships of $5 \%, 6 \%$ and $8 \% \mathrm{~K}^{-1}$.

The radar transects are discussed in Cavitte et al. $(2016,2020)$ and cut across an area loosely bound by the Concordia Trench and Little Dome C (LDC).

In a first step we investigate which surface mass balance history during the last glacial-interglacial cycle best matches the $96 \mathrm{ka}$ isochrone along transect DC-X45a. This transect spans from the northern end of the Concordia Subglacial Trench southward via EDC to LDC (thick black line in Fig. 5a). Isochrones are computed from the output of experiment B1-P1 in Sutter et al. (2019) using a scaling constant between temperature and accumulation anomalies (i.e. the per cent change in accumulation for every degree of surface air temperature change) of $3 \% \mathrm{~K}^{-1}$. Figure $5 \mathrm{~b}$ depicts the observed $96 \mathrm{ka}$ isochrone in comparison to the simulated isochrones. The simulated isochrone elevation fits the observed one reasonably well to within $\approx 2 \%-5 \%$ RMSD. According to our simulations a precipitation scaling between $5 \%$ and $6 \% \mathrm{~K}^{-1}$ (RMSD of $\approx 3.8 \%$ and $\approx 3.3 \%$ for precipitation scaling of 5 and $6 \% \mathrm{~K}^{-1}$, respectively) reproduces the $96 \mathrm{ka}$ isochrone best, which is in accordance with an icecore-based relationship of $5.9 \pm 2.2 \% \mathrm{~K}^{-1}$ for EDC (Frieler et al., 2015). This gives us confidence that the palaeo-mass balance forcing approach in Sutter et al. (2019) is valid at least for the region around Dome $\mathrm{C}$ and likely for the larger parts of the interior East Antarctic ice sheet (see Sect. 4). It is important to note that the simulations are tuned to the geothermal heat flux data from Shapiro and Ritzwoller (2004). We discuss the impact of the choice of the geothermal heat flux forcing in Sect. 3.3.

Above, we identified which palaeo-temperatureprecipitation scaling leads to the best fit of modelled and observed isochrone elevations. Making use of this palaeo-accumulation estimate we can plot the transient accumulation history at EDC during the last glacial interglacial cycle (Fig. 6a) and compare the regional temporal mean precipitation forcing during 0-9 and 9-39 ka with reconstructed palaeo-accumulation patterns at Dome $\mathrm{C}$ by Cavitte et al. (2018) (Fig. 6b). Figure 6a depicts the EDC accumulation history depending on the temperature-precipitation scaling factor. The Holocene surface mass balance fluctuates close to the present-day reference forcing derived from the regional climate model RACMO (van Wessem et al., 2014), which is used here as the present-day reference climate state (ca. $3 \mathrm{~cm} \mathrm{a}^{-1}$ ice equivalent in the Dome $\mathrm{C}$ region) and drops 

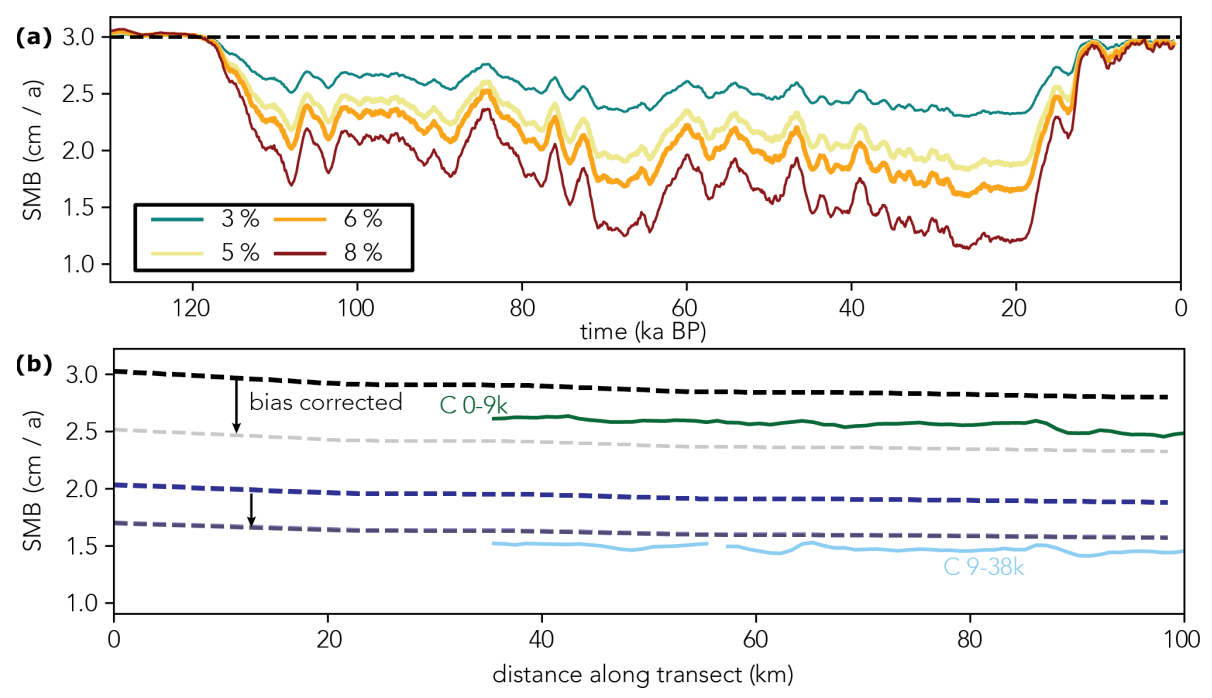

Figure 6. (a) Prescribed precipitation $\left(\mathrm{cm} \mathrm{a}^{-1}\right)$ over time at the EPICA Dome C ice-core drill site for different temperature-precipitation scaling $\left(3 \%, 5 \%, 6 \%, 8 \% \mathrm{~K}^{-1}\right)$. The temperature-precipitation scaling which produces the most realistic isochrone elevations along the transects analysed in this work is highlighted by thick lines $\left(5 \%, 6 \% \mathrm{~K}^{-1}\right)$. (b) Green and light-blue lines depict the mean 0-9 and 9-38 kyr accumulation along transect DC-X45a from Cavitte et al. (2018) compared to the simulated accumulation for the same time with a precipitation forcing with $6 \% \mathrm{~K}^{-1}$ temperature-precipitation scaling (dashed lines). The semi-transparent dashed lines depict the precipitation after accounting for the difference between the present-day reference data from van Wessem et al. (2014) and the observed modern surface mass balance estimate at EDC, which is $\approx 2.5 \mathrm{~cm} \mathrm{a}^{-1}$ (Stenni et al., 2016).

to ca. $1.7 \mathrm{~cm} \mathrm{a}^{-1}$ during the LGM. The observed modern surface mass balance at EDC is $\approx 2.5 \mathrm{~cm} \mathrm{a}^{-1}$ (Stenni et al., 2016); i.e. our present-day surface mass balance forcing is ca. $20 \%$ too high in this region. When we compare our simplified forcing with reconstructed palaeo-accumulation patterns at Dome C by Cavitte et al. (2018) our estimates of palaeo-accumulation differ by about $10 \%$ to $30 \%$. This is mostly due to the aforementioned overestimation in the 1979-2011 reference surface mass balance at EDC. It is important to note that our approach does not strive to achieve a detailed reconstruction of palaeo-accumulation as done in Cavitte et al. (2018). They fit englacial layer horizons via a 1D pseudo-steady ice-flow model (Parrenin et al., 2017), leading to more accurate estimates of the local surface mass balance along the ice divide near EPICA Dome C, while we are merely trying to establish the validity of our large-scale palaeoclimate forcing approach. Nevertheless, Fig. 6b illustrates that our palaeo-accumulation forcing provides a surface mass balance pattern along ice divides which matches more detailed reconstructions as carried out by Cavitte et al. (2018) reasonably well.

\subsection{Dome C - impact of palaeo-spin-up and model parameterisation on simulated isochrone elevation (ii)}

The modelled isochrone elevations discussed above were computed on the basis of transient snapshots of local velocity and topography fields (bedrock and surface elevation) and show a good match to observed isochrone elevations. In the following we analyse the modelled $96 \mathrm{ka}$ isochrone elevation along transect DC-X57a for three different tracer experiments, in which the velocity and ice geometry are taken from (1) the full transient ISM data from the $220 \mathrm{ka}$ palaeo-simulation with temperature-precipitation scaling of $5 \% \mathrm{~K}^{-1}$ (pal case), (2) only the present-day output of the latter (pd-pal case) and (3) the velocity and topography data from an ensemble of present-day climate equilibrium simulations (pd case) where the ice sheet is forced only by presentday surface climate and ocean temperatures. The comparison between pal and pd-pal allows us to assess the influence of the transient past surface mass balance forcing and palaeoice-flow reorganisation in pal, while the comparison between pd-pal and pd mainly illuminates the effect of the parameterisation of ice flow (ii) and the missing imprint of the palaeospin-up. In pal, tracers are advected based on the respective temporally evolving ice-sheet configuration; in pd-pal advection is based on the last time slice output (present-day) of pal (using constant velocity and topography); in pd tracers are advected via the present-day equilibrium velocity resulting from present-day climate forcing.

This will therefore elucidate the impact of the palaeospin-up and of the model parameterisation (ii) on computed isochrone elevations (Fig. 7). Figure 7 shows that the difference in isochronal elevation between pal and pd-pal is already substantial. However, it is relatively small ( $4.8 \%$ vs. $11.4 \%$ RMSD) in comparison to the difference between pal (4.8\% RMSD) and pd (20\%-56\% RMSD) despite the fact 

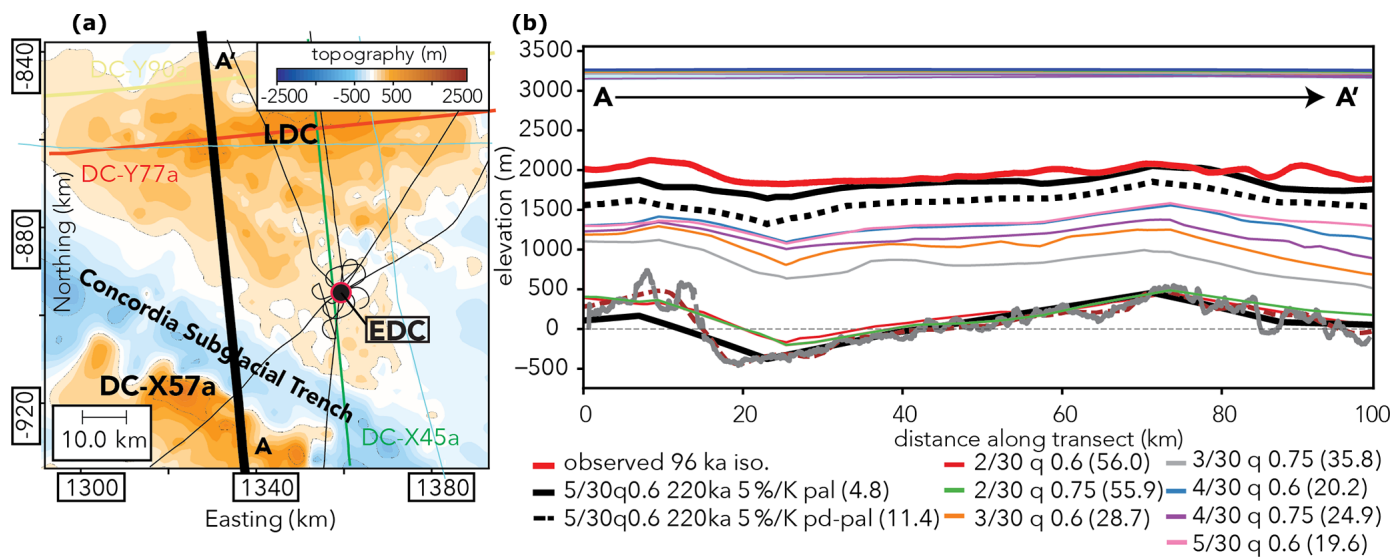

Figure 7. Comparison of the observed and modelled $96 \mathrm{ka}$ isochrone along radar profile DC-X57a (red line in right panel) in the Dome C region: (a) depicts the study area and the location of the radar transect corresponding to the simulated and observed isochrone; (b) $96 \mathrm{ka}$ observed isochrone elevation (in red), palaeoclimate simulation with $5 \% \mathrm{~K}^{-1}$ precipitation scaling (black line), present-day output of the palaeoclimate simulation (dashed black line) and present-day equilibrium simulations as well as corresponding surface elevations (coloured lines). The observed surface elevation is plotted in dark blue. Root mean square difference (\%) between observed and modelled isochrone elevation is given by the numbers in the legend of (b). Bedrock elevation in the pal model run is plotted in black and bedrock elevation derived from the radar transect in grey. The gridded $1 \mathrm{~km}$ BedMachine bedrock elevation (Morlighem et al., 2020) is plotted for comparison as well (smooth dashed red line).

that surface elevations for pd-pal and pd are very similar. All isochrone elevations simulated in the pd case are unrealistic but also show a substantial spread for the parameter range tested here (see Sect. 2.2). Increasing either the basal friction (via the till friction angle) or the parameter controlling the sliding (via $q$ ) shifts the isochrone elevation by almost a third of the local ice thickness. However, even for parameter sets which lead to a growing ice sheet under present-day climate conditions (corresponding with an ice-sheet model parameterisation which leads to high basal drag and slower vertical and horizontal ice advection), the simulated elevation of the $96 \mathrm{ka}$ isochrone is well below the observed one. This shows that it is only possible to simulate realistic isochrone elevations while achieving an overall ice-sheet shape in agreement with present-day observations if one takes into account the palaeo-evolution of the ice sheet.

Tuning an ISM to present-day observations and mass balance trends (pd) might yield a suitable fit to ice-sheet surface observations but fails to capture the integrated internal layering, which is a product of the palaeo-surface mass balance as well as of palaeo-ice dynamics. This might have important repercussions for palaeo-ice-sheet studies as well as for projections of the future sea-level contribution of the Antarctic ice sheet as the ice sheet's initial state can affect its future behaviour over centennial or even decadal timescales (Seroussi et al., 2019) due to misrepresentations for example in the parameterisation of basal friction, the internal flow fields and the thermal state as a consequence of overfitting. Ideally, to assess the impact of isochrone elevation calibration on ice-sheet-model projections, one would compare three cases where the model parameters are tuned (a) via thickness and surface velocity inversion, (b) against present-day surface observables and palaeo-proxies (ideally including a palaeospin-up), and (c) isochrone elevation calibration combined with (b). However, this is work in progress and beyond the scope of this paper.

\subsection{Impact of lower boundary conditions on simulated isochrone elevation (iii)}

Next to the uncertainties associated with palaeoclimate forcing fields and ISM parameterisations, the uncertainties in the basal boundary conditions (iii) applied in a large-scale palaeo-ISM further complicate the computation of isochrone elevations. Areas with sparse radar observations may have bed elevation estimates that differ from high-resolution radar data by several hundred metres (Karlsson et al., 2018; Morlighem et al., 2020). This can affect the basal flow regime and corresponding thermal state of the local ice column significantly. We would expect that line transects characterised by a bedrock profile in relatively good agreement with reality should yield a good agreement between modelled and observed isochrones as well. While this is true (e.g. for some areas of transect DC-X57a in the Dome C region; see Fig. 9), the assumption cannot be generalised to all East Antarctic transects discussed in this work as uncertainties in the parameterisations of ice flow (see Fig. 7), palaeoclimate forcing (Fig. 5) and geothermal heat flux (Fig. 8) can have a dominating or confounding effect on differences in the observed and modelled bedrock relief. Additionally, the impact of bedrock undulations on isochrone elevation will be stronger close to bedrock and might not be observable in relatively shallow 

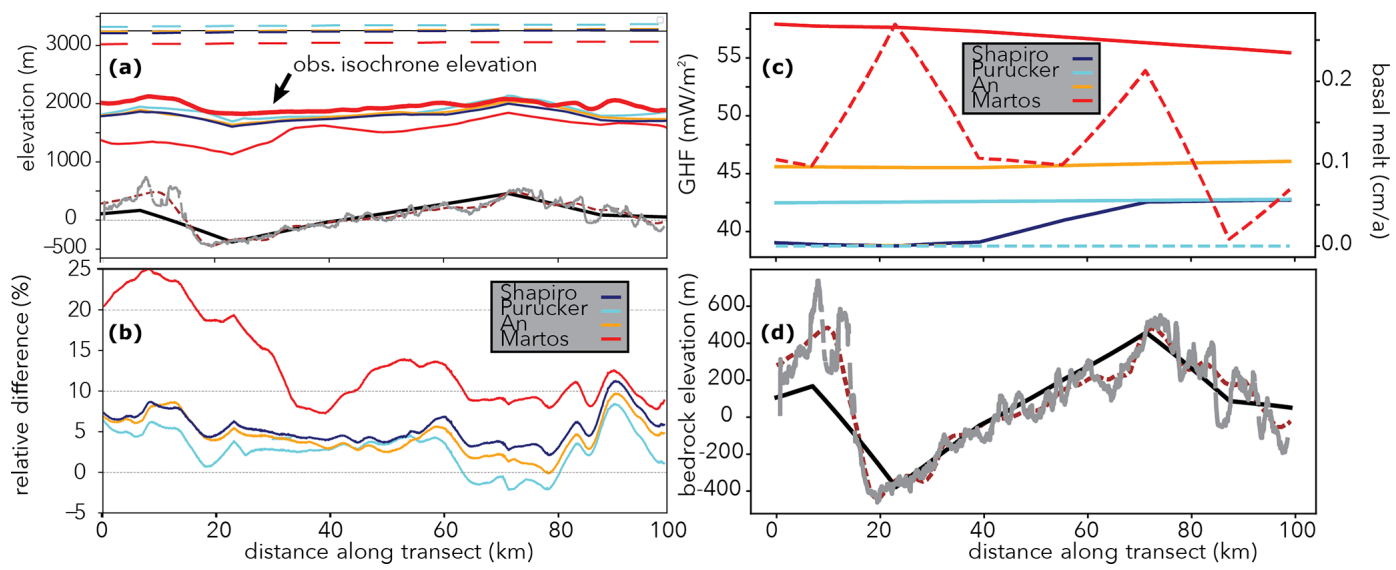

Figure 8. Illustration of model data along DC-X57a transect with a temperature-precipitation scaling of $3 \% \mathrm{~K}^{-1}$. Panel (a) shows the modelled surface (dashed lines; observed ice surface is depicted by the thin black line) and isochrone elevation under geothermal heat flux boundary conditions from Shapiro and Ritzwoller (2004), Purucker (2013), An et al. (2015), and Martos et al. (2017). Panel (b) depicts the isochrone mismatch (normalised by local ice thickness) between modelled and observed isochrone elevations. Panel (c) shows the geothermal heat flux along the transect and the associated modelled basal melt (dashed lines). Panel (d) highlights the bedrock elevation from the model simulation based on Bedmap2 (Fretwell et al., 2013) at $16 \mathrm{~km}$ resolution (black line), bedrock radar reflection (Cavitte et al., 2016) (grey line) and BedMachine Antarctica (Morlighem et al., 2020) data at $1 \mathrm{~km}$ resolution (dashed red line).

isochrones where the surface mass balance is the dominating factor.

A further challenge complicating the comparison between simulated and observed isochrone elevations is the largely unknown distribution of geothermal heat at the base of the ice, which is only inferred indirectly and exhibits large differences between datasets from Shapiro and Ritzwoller (2004), Purucker (2013), An et al. (2015), and Martos et al. (2017). Comparison with simulations employing other datasets shows that the modelled isochrones fit well for geothermal heat flux from Purucker (2013) and An et al. (2015) but fail to reproduce the approximate isochrone elevation for the high geothermal heat flux from Martos et al. (2017). The Martos et al. (2017) dataset produces widespread basal melting beyond $\left(1 \mathrm{~mm} \mathrm{a}^{-1}\right)$ in the region (see Figs. 8 and 4c). Geothermal heat flux is uncertain for most parts of the Antarctic ice sheet, and regional differences between published datasets (Fig. 8) can be substantial (Burton-Johnson et al., 2020; Talalay et al., 2020). Local basal melting occurs under forcing with the Shapiro and Ritzwoller (2004) dataset as well but is largely limited to $0-1 \mathrm{~mm} \mathrm{a}^{-1}$ and lies between $0.25-0.5 \mathrm{~mm} \mathrm{a}^{-1}$ around EDC. The computed basal melt rates with geothermal heat flux from Shapiro and Ritzwoller (2004) and a temperatureprecipitation scaling of $6 \% \mathrm{~K}^{-1}$ are similar to the ones in Passalacqua et al. (2017), which are empirically determined to fit the EPICA Dome C ice-core age scale. A more complete assessment of the relative influence of basal and surface boundary conditions as well as model parameterisations on East Antarctic isochrone elevations across the whole ice column is beyond the scope of this study but could be the focus of an upcoming palaeo-ISM intercomparison.

\subsection{Caveats to modelling isochrones with large-scale ISMs}

Differences between modelled isochrones (based on palaeovelocity fields) and their observed elevation above bedrock are generally small for all isochrones sampled in this study that are younger than the LIG $(<120 \mathrm{ka}$ : RMSD $<5 \%)$. It is striking, however, that for isochrones older than $120 \mathrm{ka}$ the gap between model results and observation widens (see Fig. 9). Due to the lack of climate model data for glacials and interglacials preceding the LIG, we estimated the climate forcing before $130 \mathrm{ka}$ to be a linear combination between the climate state of the LGM and the LIG using the EPICA Dome C deuterium record as an index to interpolate between the two climate states (see Sect. 2.1 in Sutter et al., 2019). Naturally, this approach is just an approximation of the actual transient climate conditions and therefore will necessarily lead to discrepancies in the surface mass balance as well as the ocean forcing. Another potential cause of the relatively poor representation of isochrones before $120 \mathrm{ka}$ is the high circum-Antarctic subsurface ocean temperature peak assumed for the LIG (ca. $2^{\circ} \mathrm{C}$ ). Due to coastal thinning and potentially grounding-line retreat caused by elevated ocean temperatures, this might lead to an exaggerated ice flow in the major drainage basins such as the Wilkes Basin (see Fig. 10) or the Aurora Basin, in turn potentially affecting even remote regions such as Dome C. In fact, the model-data-observation mismatch is especially poor for the sections of the Dome C transects close to the Aurora Subglacial Basin (see Fig. 9b), which could also point to an issue with the parameterisation of basal drag in subglacial basins (see Sect. 4). 


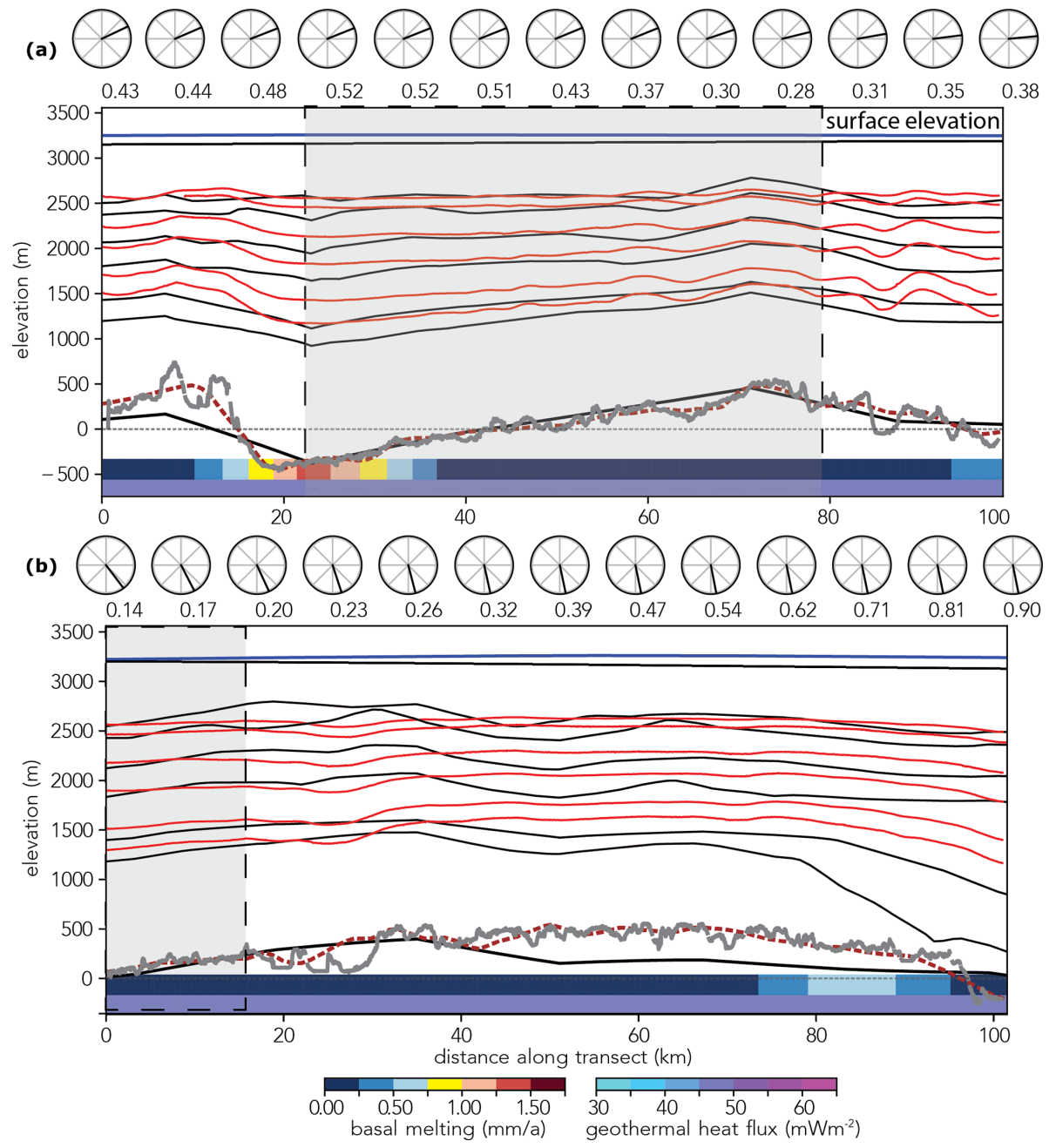

Figure 9. Modelled (black lines) and observed isochrones (red lines 38, 48, 74, 96, 130 and 160 ka from top to bottom) for transect DCX57a (a) and DC-Y77a (b) (orientation from left to right as depicted in Fig. 7a). The vertical grey bars highlight areas with low elevation differences in the low-resolution model bedrock input (black line) compared to the high-resolution radar observations (grey line), which generally correspond to a good match of modelled and observed isochrones. Bedrock and surface elevation in the model runs is plotted in black. Observed surface elevation is plotted in dark blue. The $1 \mathrm{~km}$ BedMachine data (Morlighem et al., 2020) are depicted by the dashed red line. The labelled circles denote the surface flow and magnitude in $\mathrm{m} \mathrm{a}^{-1}$ relative to the direction of the transect. The coloured bars on the bottom depict the geothermal heat flux (Shapiro and Ritzwoller, 2004) and the computed basal melt rate along the transect.

\section{Large-scale modelling of the internal architecture of the East Antarctic ice sheet}

In the following, we expand our view to the whole of the East Antarctic ice sheet, assessing how valid the choices of model parameters and the palaeo-accumulation forcing derived from Dome $\mathrm{C}$ are when it comes to simulating the evolution of the ice sheet. The focus on the EDC ice-core region in the previous section allowed us to appreciate the impact of uncertain forcing fields and bedrock elevation on a relatively small length scale $(100 \mathrm{~km})$. We now turn to larger distances, where the Dome C-derived transient palaeoclimate forcing and model optimisation might lead to more pronounced divergence between the modelled isochrone elevations and the radar data. We first assess the $90 \mathrm{ka}$ isochrone along transect CEA-10 from Winter et al. (2019) (see Fig. 10). It starts close to Talos Dome, crossing the upper reaches of the Wilkes Subglacial Basin, after which it traverses the Concordia Subglacial Trench, passing EDC and LDC and finally arching upwards, ending at Lake Vostok (total distance ca. $1500 \mathrm{~km}$ ). In the second part of this section we discuss the isochrone geometry between Dome Fuji and the EPICA Dronning Maud Land ice core (EDML). 

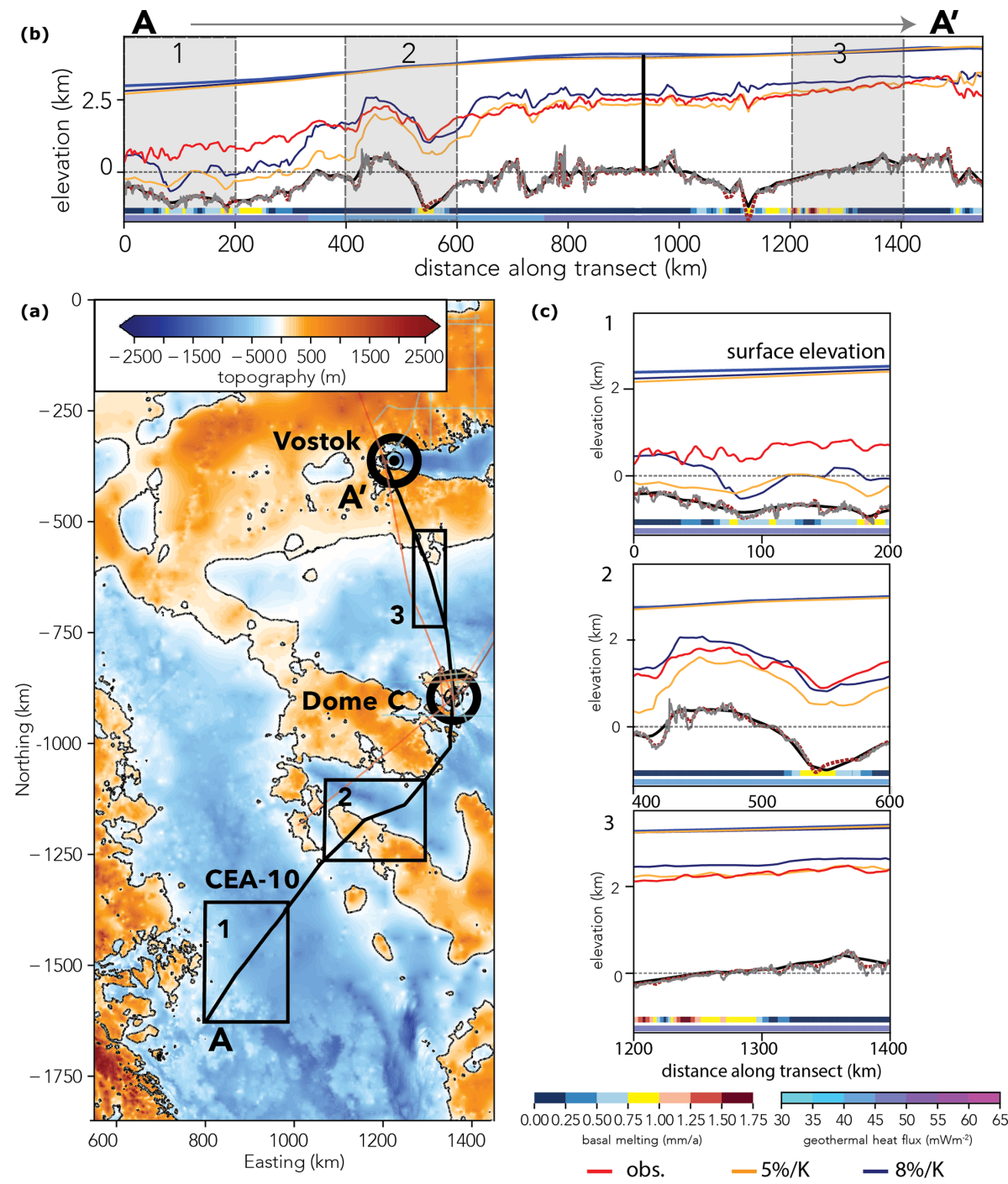

Figure 10. Overview of transect CEA-10. Panel (a) shows the bedrock elevation from Morlighem et al. (2020) at $1 \mathrm{~km}$ resolution overlain by the CEA-10 transect in black and other radar transects analysed in this study (thin coloured lines). Panels (b) and (c) illustrate the ice surface (observed: dark blue; modelled: blue $\left(8 \% \mathrm{~K}^{-1}\right)$, yellow $\left(5 \% \mathrm{~K}^{-1}\right)$ ), bedrock and isochrone elevation of the $90 \mathrm{ka}$ radar reflector (modelled: blue $\left(8 \% \mathrm{~K}^{-1}\right)$, yellow $\left(5 \% \mathrm{~K}^{-1}\right)$; observed: red) along transect CEA-10 (the position of the EDC ice core is illustrated by the vertical black line in panel b). Bedrock elevation in the pal model run is plotted in black and the BedMachine Antarctica $1 \mathrm{~km}$ grid resolution bedrock in red. Shaded areas in (b) are shown additionally in a detailed view (c). Sea level (zero-elevation) is depicted by the dotted black line. The coloured bars on the bottom of (b) and (c) depict the geothermal heat flux (Shapiro and Ritzwoller, 2004) and the computed basal melt rate along the transect.

\subsection{Simulated isochrone elevation along the Talos Dome - Lake Vostok transect}

Figure 10 illustrates nicely that there are two main regimes covered by profile CEA-10. The northern half of the transect close to Talos Dome (bottom left in Fig. 10) is dominated by the imprint of the Wilkes Subglacial Basin, with a large misfit between the modelled and observed isochrone $(\approx 26 \%$ RMSD along kilometres $0-500$ in Fig. 10 compared to $\approx 8.3 \%$ and $\approx 4.8 \%$ along kilometres $500-1000$ and $1000-1500$, respectively). The striking excursions of the modelled isochrone elevation in Fig. 10 point towards an internal vertical ice motion that is too fast. This could be due to the general heuristics involved in determining the basal friction in subglacial basins (low friction in deep basins). Furthermore, past elevated-ice-flow episodes of the marine Wilkes Basin ice sheet caused by thinning of the coastal ice cover for example during interglacials (Sutter et al., 2020) could have mediated drawdown of isochrone elevation. While a spatially varying temperature-precipitation relationship could also affect the isochrone elevation in this region, this does not seem to be the case here. We show 
this by computing the $90 \mathrm{ka}$ isochrone elevation in a palaeosimulation with a temperature-precipitation relationship of $8 \% \mathrm{~K}^{-1}$. This scenario cannot mitigate the drop in elevation in the first $300 \mathrm{~km}$ of the transect and exacerbates the deviation between simulated and observed isochrone elevation along kilometres $500-1500(\approx 16.7 \%$ RMSD along kilometres $0-500$ in Fig. 10 compared to $\approx 8.7 \%$ and $\approx 7.8 \%$ along kilometres 500-1000 and 1000-1500, respectively). We did not test temperature-precipitation relationships higher than $8 \% \mathrm{~K}^{-1}$ as they would be beyond what is reconstructed from East Antarctic ice cores. Geothermal heat flux can also be ruled out as for the most part the thermal regime in the dataset from Shapiro and Ritzwoller (2004) at Dome C is similar or even lower. On the basis of the boundary conditions used here, we suggest that the main reason for the isochrone mismatch lies in the parameterisation of basal drag and ice flow. The basal friction in the model is a function of bedrock elevation (see Sect. 2.2) and decreases with depth; therefore it is lower in bedrock depressions, especially below sea level, where sliding is thus higher. Also, the relatively coarse resolution $(16 \mathrm{~km})$ used here leads to a "smoothed-out" bedrock profile (see Fig. 8), potentially favouring faster basal ice flow. A "rougher" bedrock profile might impede sliding in drainage regions. Another aspect could be the choice of the so-called "enhancement factor" in the shallow-ice approximation $\mathrm{SIA}_{e}$, which is a crude tuning parameter to accommodate for anisotropic ice. Here, $\mathrm{SIA}_{\mathrm{e}}=1.0$ which is low compared to values used in other studies (generally, a lower value of SIA $\mathrm{S}_{\mathrm{e}}$ leads to slower ice flow), so we do not expect that the enhancement factor plays a dominant role. Modelled isochrone elevations in the present-day equilibrium ensemble (pd case) are far off the observed target elevation throughout the CEA-10 transect (see Fig. 11). This finding is in agreement with the Dome $\mathrm{C}$ region pd case (Sect. 3.2).

\subsection{Simulated isochrone elevation along the Dome Fuji - Dronning Maud Land transect}

We now focus on the $74 \mathrm{ka}$ isochrone connecting Dome Fuji $\left(77^{\circ} 32^{\prime} \mathrm{S}, 38^{\circ} 70^{\prime} \mathrm{E}\right)$ and the EDML ice core $\left(75^{\circ} 0^{\prime} \mathrm{S}\right.$, $\left.0^{\circ} 068^{\prime} \mathrm{E}\right)$. Figure 12 illustrates the topographic characteristics of the area enclosing Dome Fuji and EDML. In contrast to Dome $\mathrm{C}$, which is surrounded by bedrock below sea level in the outskirts of the Aurora Subglacial Basin, the ice bed at and around Dome Fuji is elevated above sea level for several hundreds of kilometres in every direction. This means that the yield stress computed by the ISM will be very high in a large area, making the impact of sliding on internal ice velocities negligible. Both transects DML-VIII23 and DML-IV24 are characterised by mountainous subglacial terrain above sea level (see Fig. 12a). Any mismatches between the observed and modelled isochrone elevations are most probably due to uncertainties in the climate forcing or computed basal melt patterns. Basal melting at the bed of the ice along the radar tracks is largely unknown, as is the

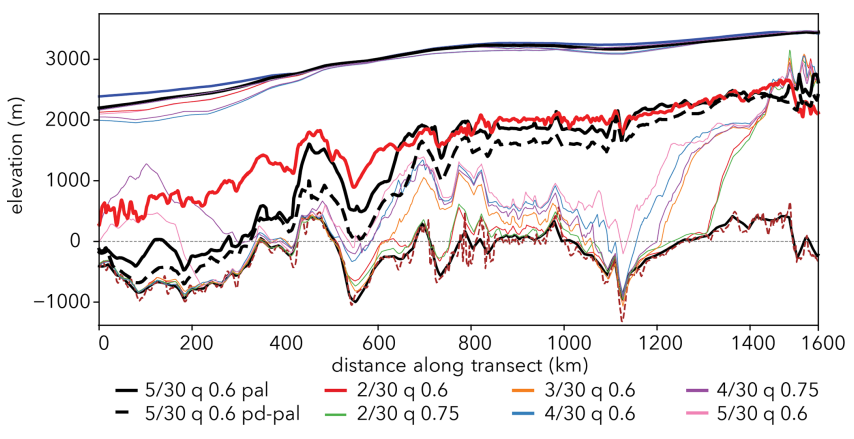

Figure 11. Simulated and observed isochrone elevations along transect CEA-10. The thick red line depicts the observed $90 \mathrm{ka}$ radar reflector, the black line the $220 \mathrm{ka}$ palaeo-simulation with a palaeo-precipitation-temperature relationship of $5 \% \mathrm{~K}^{-1}$. The dashed black line shows the isochrone elevation computed with the respective present-day time slice (pd-pal case) of the palaeosimulation (pal). The thin coloured lines represent the simulated isochrone and surface elevation from the present-day equilibrium ensemble (pd). Bedrock elevation in the pal model run is plotted in black and bedrock elevation derived from Morlighem et al. (2020) in red. The observed surface elevation is plotted in dark blue.

temporal palaeo-accumulation pattern. A direct comparison to proxy or observational data is therefore not feasible. In the future, observation-based estimates of the presence or absence of basal melt (e.g. Fujita et al., 2012; Passalacqua et al., 2017; Karlsson et al., 2018) could be utilised to locally attribute mismatches between modelled and observed isochrone elevations to inconsistencies in basal melting between models and observations.

We limit ourselves to a qualitative discussion of the model data mismatch trying to identify persistent patterns. Looking at DML-VIII23, the modelled isochrone elevation fits well with the observed radar data (RMSD $<5 \%$ for the whole transect) and is of similar accuracy as for the $100 \mathrm{~km}$ Dome C data for the same transect age (RMSD 3.5\%-5.0\%). In contrast to the lower half of CEA-10 (previous section), which is situated above a deep bedrock depression associated with low basal friction in the model, the whole transect DML-VIII23 is characterised by relatively flat bedrock above sea level. The comparison between DML-VIII23 and CEA-10 potentially highlights a methodological deficiency (leading to unrealistic internal flow and basal sliding) as the isochrone mismatch in CEA-10 cannot be remedied by a surface mass balance correction.

Modelled isochrone elevations based on simulations employing inversion techniques to determine basal friction and/or a palaeo-ensemble covering a larger parameter spread would be necessary to assess whether this mismatch can be further reduced using state-of-the-art models today.

In the case of DML-IV24 a slightly different picture emerges. For the first half of the transect, the modelled isochrone is in very good agreement with the observed elevation data (except in areas with strong deviations between the 

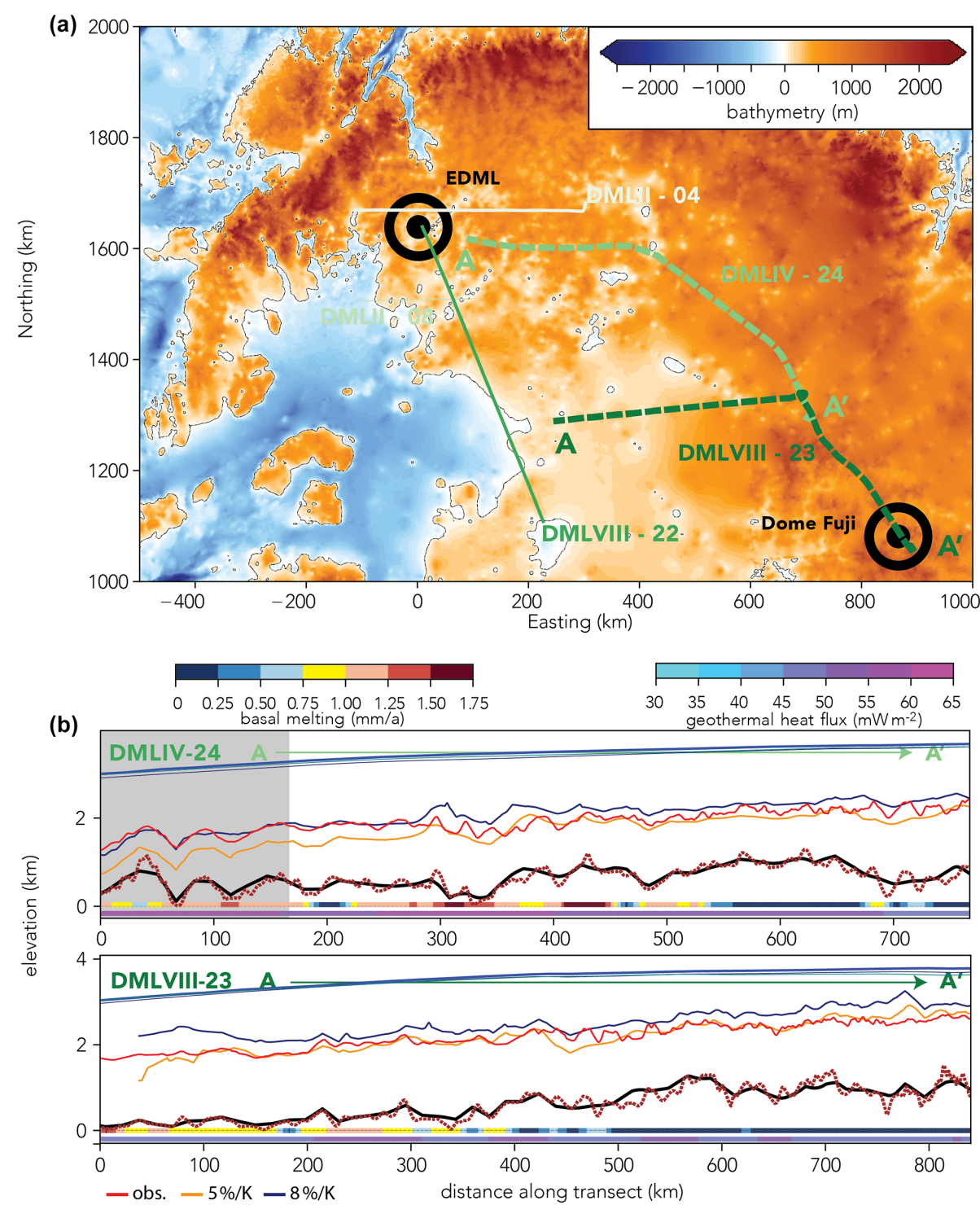

Figure 12. Overview of transect DML VIII-23 and IV-24. Panel (a) shows the bedrock elevation from Morlighem et al. (2020) at $1 \mathrm{~km}$ resolution overlain by the DML transects in green and other radar transects analysed in this study (thin coloured lines). Panel (b) illustrates the ice surface, bedrock and isochrone elevation of the $74 \mathrm{ka}$ radar reflector (modelled: blue $\left(8 \% \mathrm{~K}^{-1}\right)$, yellow $\left(5 \% \mathrm{~K}^{-1}\right)$; observed: red). The model bedrock elevation is depicted in black, while the original radar data and the BedMachine Antarctica $1 \mathrm{~km}$ grid are plotted in red. The coloured bars on the bottom of (b) depict the geothermal heat flux and the computed basal melt rate along the transect.

$16 \mathrm{~km}$ Bedmap2 topography and the high-resolution radar observation), but the second half of the transect shows large deviations in the isochrone elevation, leading to an overall RMSD of ca. $10 \%$ for the whole transect. In this case, identifying the causes for the mismatch is not straightforward as the bedrock is above sea level along the whole transect, and there is no clear correlation between elevated basal melt rates and dips in modelled isochrone elevation. One potential reason could be a relationship between temperature and precipitation anomalies in the EDML region which strongly differs from the continental-scale temperature-precipitation scaling of ca. $5 \pm 1 \% \mathrm{~K}^{-1}$. This would affect the surface mass balance forcing and therefore the elevation of the isochrone. However, the proxy-based palaeo-precipitation-temperature relationship at EDML is very similar to the continental, mean albeit with considerable uncertainties of $\pm 2.8 \%$ for EDML (Frieler et al., 2015). In fact, using the ISM results of a simulation with a precipitation-temperature relationship of $8 \% \mathrm{~K}^{-1}$, which is at the upper end of reconstructions for EDML, the match of the computed isochrone elevation close to EDML is improved considerably (see Fig. 12). Thus, the assumption of a simple and spatially uniform accumulation and temperature scaling may be valid on the high plateau of the East Antarctic sheet but will not necessarily hold for areas 
closer to the coast, where synoptic activity can dominate the spatial and temporal variability in precipitation (Welker et al., 2014). This could only be remedied in coupled atmosphereice-sheet model runs that are able to resolve such synoptic activity. For computational reasons, however, this is currently not possible for such long-term runs as performed in this study. One potential solution would be to use a spatially heterogenous accumulation-temperature scaling informed by both coastal and interior ice-core reconstructions.

\section{Conclusions}

We present the first attempt to constrain Antarctic palaeoclimate forcing and parameterisations of ice flow in a continental-scale ice-sheet model by comparison of simulated englacial layers to a pool of observed Antarctic isochrones.

- We are able to reconstruct most large-scale englacial layer features of the observed isochrones and show that it is possible to simulate the observed internal structure of the Antarctic ice sheet even at coarse resolution. We identify mismatches between modelled and observed isochrone elevations, which can be traced back to the transient palaeoclimate forcing employed in our model runs that makes use of a linear palaeo-temperatureprecipitation relationship. The forcing is derived from ice-core reconstructions in combination with palaeoclimate model data. This does not take into account the spatial heterogeneity of palaeo-temperatureprecipitation relationships and effects of synoptic precipitation variability. Our isochrone modelling efforts motivate the use of a regionally refined temperatureprecipitation scaling to improve palaeo-ice-sheet simulations and consequently the palaeo-spin-up for modelbased future projections.

- We further show that our computed isochrone elevations are in very good agreement (within $\pm 5 \%$ RMSD of the local ice thickness) with observations in slowly flowing regions such as at or near ice divides, especially at locations where the ice-core-based proxy reconstruction of the temperature-precipitation scaling matches the one used in the forcing. However, we find key isochrone elevation mismatches in the proximity of or above marine glaciated areas of the Antarctic ice sheet, which points towards a poorly constrained parameterisation of basal drag. There seems to be a systematic overestimation of vertical advection over subglacial basins and in drainage sectors. This is most probably a commonality of all ISM set-ups using heuristics for basal friction similar to those we use here, i.e. the majority of ISMs used for palaeo-studies. This raises the question of whether palaeo-simulations and projections of ice dynamics in subglacial basins might be subject to a systematic bias.
We show that using englacial layers as a tuning target in ice-sheet modelling is ideally suited to identify such biases because surface observables such as ice-sheet elevation do not necessarily reveal inconsistencies in the subsurface flow field. Expanding the existing radar observations into regions of dynamic ice flow away from ice divides and over subglacial basins would provide invaluable constraints for palaeo-ISM simulations.

- The reproducibility of isochrones dramatically increases if the ice sheet has been simulated transiently over the last several glacial-interglacial cycles. In contrast, flow fields computed in equilibrium simulations under constant present-day forcing produce isochrone elevation mismatches of up to two-thirds of the local ice thickness. Varying the parameter space relevant for basal sliding for a set of parameters that produce an equilibrium sea-level-equivalent ice volume of the Antarctic ice sheet within $\pm 2 \mathrm{~m}$ of present-day observations cannot remedy this mismatch. This points towards critical misrepresentations of the ice sheet's internal flow for model set-ups where only present-day climate forcing is taken into account, and the model is solely tuned against present-day 2D and 1D observables. Even small biases (e.g. due to overfitting against uncertain input fields) in the initial model state can impact ice-sheet dynamics and therefore estimates of future ice-sheet sea-level contributions. We make the case that the palaeo-evolution of an ice sheet should be considered both for reconstructions and projections of icesheet changes and that isochrones are ideally suited for this purpose.

- When using isochrones as a tuning target for palaeoISMs, two key uncertainties prove difficult to account for: (1) geothermal heat flux fields remain poorly constrained (new, e.g. Stal et al., 2021, and upcoming datasets might reduce this uncertainty) and can have a strong influence on isochrone elevations; (2) uncertain bedrock elevation in regions with gaps in radar surveys affects modelled isochrone elevations, especially for isochrones close to bedrock. However, for areas covered by high-resolution radar transects, this aspect can be quantified by comparison to the model bedrock elevation. Combining isochrone elevations, present-day observables and palaeo-proxy data in the calibration of ice-sheet model set-ups helps to mitigate the aforementioned uncertainties and prevent overfitting.

- A model intercomparison investigating isochrone elevations based on a variety of model physics and forcings could shed light on systematic misrepresentations of ice flow and, thus, internal stratigraphy in currentgeneration ISMs. For example, the impact of different calibrations of basal drag on modelled isochrone elevations, such as inversion methods based on surface ele- 
vation and ice flow, could be elucidated in such an intercomparison. Our post-processing approach would allow for such an intercomparison as it forgoes the need to implement a Lagrangian tracer module into the respective ISM. We make the case that the internal stratigraphy of the Antarctic ice sheet can serve as a valuable data benchmark for continental ice-sheet modelling as it provides a three-dimensional tuning target which is imprinted with the complete climate and flow history of the ice sheet.

We conclude that this approach should be used alongside traditionally employed tuning targets such as ice volume, surface velocity or grounding-line positions. While analysing the match of an ISM simulation with the internal stratigraphy is not as straightforward as using surface observables, it could improve both palaeo-ice-sheet reconstructions and sea-level projections due to more realistic initial ice-sheet configurations. Efforts such as AntArchitecture's to provide a compilation of all observed englacial layers will provide an invaluable data benchmark for future ice-sheet modelling efforts. Looking ahead, it would be desirable to develop a standard protocol to tune ISMs against the internal stratigraphy of the Antarctic ice sheet. This would facilitate the evaluation of a new generation of model simulations which are constrained by the climate and ice dynamic memory encapsulated within the ice.

Code and data availability. Both PISM and OceanParcels are open-source and available via https://pism-docs.org/wiki/doku.php (last access: 4 August 2021, The PISM authors, 2021) and http: //oceanparcels.org/index.html (last access: 4 August 2021), respectively. The isochrones from Winter et al. (2019) are available via Pangaea https://doi.pangaea.de/10.1594/PANGAEA.895528 (Winter et al., 2018). All model data are available upon request.

Video supplement. The Video supplement illustrates the tracer migration from $90-0 \mathrm{ka}$ across the East Antarctic ice sheet. Tracers are seeded at the surface at $90 \mathrm{ka}$ and transported with the ice flow over time. Colouring illustrates absolute tracer elevation. The Video supplement is available at https://doi.org/10.5446/50125.

Author contributions. JS devised the experiments and ran the simulations. JS, HF and OE carried out the analysis. JS wrote the manuscript with contributions from $\mathrm{HF}$ and $\mathrm{OE}$.

Competing interests. Author Olaf Eisen is a member of the editorial board of the journal.

Disclaimer. Publisher's note: Copernicus Publications remains neutral with regard to jurisdictional claims in published maps and institutional affiliations.
Special issue statement. This article is part of the special issue "Oldest Ice: finding and interpreting climate proxies in ice older than 700000 years (TC/CP/ESSD inter-journal SI)". It is not associated with a conference.

Acknowledgements. We would like to thank Marie Cavitte, Gwendolyn Leysinger Vieli, Anna Winter, Lucas Beem and David Ashmore for providing the isochrone data and helpful discussions as well as Philippe Delandmeter and Victor Onink for their support with setting up OceanParcels for the use with PISM data. JS is grateful for funding from the Deutsche Forschungsgemeinschaft under personal grant SU 1166/1-1 (WANT-Ice project). Hubertus Fischer gratefully acknowledges the long-term support by the Swiss National Science Foundation (SNSF). Development of PISM is supported by NSF grants PLR-1603799 and PLR-1644277 and NASA grant NNX17AG65G.

Financial support. This research has been supported by the Deutsche Forschungsgemeinschaft (grant no. SU 1166/1-1).

Review statement. This paper was edited by Pippa Whitehouse and reviewed by two anonymous referees.

\section{References}

Albrecht, T., Winkelmann, R., and Levermann, A.: Glacial-cycle simulations of the Antarctic Ice Sheet with the Parallel Ice Sheet Model (PISM) - Part 2: Parameter ensemble analysis, The Cryosphere, 14, 633-656, https://doi.org/10.5194/tc-14633-2020, 2020.

An, M. J., Wiens, D. A., Zhao, Y., Feng, M., Nyblade, A., Kanao, M., Li, Y. S., Maggi, A., and Leveque, J. J.: Temperature, lithosphere-asthenosphere boundary, and heat flux beneath the Antarctic Plate inferred from seismic velocities, J. Geophys. Res.-Sol. Ea., 120, 8720-8742, https://doi.org/10.1002/2015jb011917, 2015.

Ashmore, D. W., Bingham, R. G., Ross, N., Siegert, M., Jordan, T. A., and Mair, D. W. F.: Englacial Architecture and Age-Depth Constraints Across the West Antarctic Ice Sheet, Geophys. Res. Lett., 47, e2019GL086663, https://doi.org/10.1029/2019GL086663, 2020.

Bazin, L., Landais, A., Lemieux-Dudon, B., Toyé Mahamadou Kele, H., Veres, D., Parrenin, F., Martinerie, P., Ritz, C., Capron, E., Lipenkov, V., Loutre, M.-F., Raynaud, D., Vinther, B., Svensson, A., Rasmussen, S. O., Severi, M., Blunier, T., Leuenberger, M., Fischer, H., Masson-Delmotte, V., Chappellaz, J., and Wolff, E.: An optimized multi-proxy, multi-site Antarctic ice and gas orbital chronology (AICC2012): 120-800 ka, Clim. Past, 9, 17151731, https://doi.org/10.5194/cp-9-1715-2013, 2013.

Beem, L. H., Young, D. A., Greenbaum, J. S., Blankenship, D. D., Cavitte, M. G. P., Guo, J., and Bo, S.: Aerogeophysical characterization of Titan Dome, East Antarctica, and potential as an ice core target, The Cryosphere, 15, 1719-1730, https://doi.org/10.5194/tc-15-1719-2021, 2021. 
Bentley, M. J., Cofaigh, C. O., Anderson, J. B., Conway, H., Davies, B., Graham, A. G. C., Hillenbrand, C. D., Hodgson, D. A., Jamieson, S. S. R., Larter, R. D., Mackintosh, A., Smith, J. A., Verleyen, E., Ackert, R. P., Bart, P. J., Berg, S., Brunstein, D., Canals, M., Colhoun, E. A., Crosta, X., Dickens, W. A., Domack, E., Dowdeswell, J. A., Dunbar, R., Ehrmann, W., Evans, J., Favier, V., Fink, D., Fogwill, C. J., Glasser, N. F., Gohl, K., Golledge, N. R., Goodwin, I., Gore, D. B., Greenwood, S. L., Hall, B. L., Hall, K., Hedding, D. W., Hein, A. S., Hocking, E. P., Jakobsson, M., Johnson, J. S., Jomelli, V., Jones, R. S., Klages, J. P., Kristoffersen, Y., Kuhn, G., Leventer, A., Licht, K., Lilly, K., Lindow, J., Livingstone, S. J., Masse, G., McGlone, M. S., McKay, R. M., Melles, M., Miura, H., Mulvaney, R., Nel, W., Nitsche, F. O., O’Brien, P. E., Post, A. L., Roberts, S. J., Saunders, K. M., Selkirk, P. M., Simms, A. R., Spiegel, C., Stolldorf, T. D., Sugden, D. E., van der Putten, N., van Ommen, T., Verfaillie, D., Vyverman, W., Wagner, B., White, D. A., Witus, A. E., Zwartz, D., and Consortium, R.: A communitybased geological reconstruction of Antarctic Ice Sheet deglaciation since the Last Glacial Maximum, Quatern. Sci. Rev., 100, 1-9, https://doi.org/10.1016/j.quascirev.2014.06.025, 2014.

Bingham, R.: Report of AntArchitecture Workshop, July 2017, availalable at: https://www.scar. org/library/science-4/geosciences/antarchitecture/

5240-antarchitecture-workshop-2017/ (last access: 4 August 2021), 2020.

Born, A.: Tracer transport in an isochronal ice-sheet model, J. Glaciol., 63, 22-38, https://doi.org/10.1017/jog.2016.111, 2017.

Bueler, E. and Brown, J.: Shallow shelf approximation as a "sliding law" in a thermodynamically coupled ice sheet model, J. Geophys. Res., 114, F03008, https://doi.org/10.1029/2008JF001179, 2009.

Bueler, E., Lingle, C. S., and Brown, J.: Fast computation of a viscoelastic deformable Earth model for ice-sheet simulations, Ann. Glaciol., 46, 97-105, https://doi.org/10.3189/172756407782871567, 2007.

Burton-Johnson, A., Dziadek, R., and Martin, C.: Review article: Geothermal heat flow in Antarctica: current and future directions, The Cryosphere, 14, 3843-3873, https://doi.org/10.5194/tc-143843-2020, 2020.

Cavitte, M. G. P., Blankenship, D. D., Young, D. A., Schroeder, D. M., Parrenin, F., Lemeur, E., Macgregor, J. A., and Siegert, M. J.: Deep radiostratigraphy of the East Antarctic plateau: connecting the Dome $\mathrm{C}$ and Vostok ice core sites, J. Glaciol., 62, 323-334, https://doi.org/10.1017/jog.2016.11, 2016.

Cavitte, M. G. P., Parrenin, F., Ritz, C., Young, D. A., Van Liefferinge, B., Blankenship, D. D., Frezzotti, M., and Roberts, J. L.: Accumulation patterns around Dome C, East Antarctica, in the last $73 \mathrm{kyr}$, The Cryosphere, 12, 1401-1414, https://doi.org/10.5194/tc-12-1401-2018, 2018.

Cavitte, M. G. P., Young, D. A., Mulvaney, R., Ritz, C., Greenbaum, J. S., Ng, G., Kempf, S. D., Quartini, E., Muldoon, G. R., Paden, J., Frezzotti, M., Roberts, J. L., Tozer, C. R., Schroeder, D. M., and Blankenship, D. D.: A detailed radiostratigraphic data set for the central East Antarctic Plateau spanning the last half million years, Earth Syst. Sci. Data Discuss. [preprint], https://doi.org/10.5194/essd-2020-393, in review, 2020.
Clarke, G. K. C., Marshall, S. J., Rybak, O., and Huybrechts, P.: A comparison of Eulerian and Lagrangian methods for dating in numerical ice-sheet models, Ann. Glaciol., 37, 150-158, 2003.

Clarke, G. K. C., Lhomme, N., and Marshall, S. J.: Tracer transport in the Greenland ice sheet: three-dimensional isotopic stratigraphy, Quatern. Sci. Rev., 24, 155-171, https://doi.org/10.1016/J.Quascirev.2004.08.021,2005.

DeConto, R. M. and Pollard, D.: Contribution of Antarctica to past and future sea-level rise, Nature, 531, 591-597, https://doi.org/10.1038/nature17145, 2016.

Delandmeter, P. and van Sebille, E.: The Parcels v2.0 Lagrangian framework: new field interpolation schemes, Geosci. Model Dev., 12, 3571-3584, https://doi.org/10.5194/gmd-123571-2019, 2019.

Dutton, A., Carlson, A. E., Long, A. J., Milne, G. A., Clark, P. U., DeConto, R., Horton, B. P., Rahmstorf, S., and Raymo, M. E.: Sea-level rise due to polar ice-sheet mass loss during past warm periods, Science, 349, aaa4019, https://doi.org/10.1126/science.aaa4019, 2015.

Edwards, T. L., Brandon, M. A., Durand, G., Edwards, N. R., Golledge, N. R., Holden, P. B., Nias, I. J., Payne, A. J., Ritz, C., and Wernecke, A.: Revisiting Antarctic ice loss due to marine ice-cliff instability, Nature, 566, 58-64, https://doi.org/10.1038/s41586-019-0901-4, 2019.

Edwards, T. L., Nowicki, S., Marzeion, B., Hock, R., Goelzer, H., Seroussi, H., Jourdain, N. C., Slater, D. A., Turner, F. E., Smith, C. J., McKenna, C. M., Simon, E., Abe-Ouchi, A., Gregory, J. M., Larour, E., Lipscomb, W. H., Payne, A. J., Shepherd, A., Agosta, C., Alexander, P., Albrecht, T., Anderson, B., Asay-Davis, X., Aschwanden, A., Barthel, A., Bliss, A., Calov, R., Chambers, C., Champollion, N., Choi, Y., Cullather, R., Cuzzone, J., Dumas, C., Felikson, D., Fettweis, X., Fujita, K., Galton-Fenzi, B. K., Gladstone, R., Golledge, N. R., Greve, R., Hattermann, T., Hoffman, M. J., Humbert, A., Huss, M., Huybrechts, P., Immerzeel, W., Kleiner, T., Kraaijenbrink, P., Le clec'h, S., Lee, V., Leguy, G. R., Little, C. M., Lowry, D. P., Malles, J.-H., Martin, D. F., Maussion, F., Morlighem, M., O’Neill, J. F., Nias, I., Pattyn, F., Pelle, T., Price, S. F., Quiquet, A., Radić, V., Reese, R., Rounce, D. R., Rückamp, M., Sakai, A., Shafer, C., Schlegel, N.-J., Shannon, S., Smith, R. S., Straneo, F., Sun, S., Tarasov, L., Trusel, L. D., Van Breedam, J., van de Wal, R., van den Broeke, M., Winkelmann, R., Zekollari, H., Zhao, C., Zhang, T., and Zwinger, T.: Projected land ice contributions to twenty-first-century sea level rise, Nature, 593, 74-82, https://doi.org/10.1038/s41586-021-03302-y, 2021.

Eisen, O., Wilhelms, F., Steinhage, D., and Schwander, J.: Improved method to determine RES-reflector depths from ice-core profiles of permittivity and conductivity, J. Glaciol., 52, 299-310, https://doi.org/10.3189/172756506781828674, 2006.

Feldmann, J., Albrecht, T., Khroulev, C., Pattyn, F., and Levermann, A.: Resolution-dependent performance of grounding line motion in a shallow model compared with a full-Stokes model according to the MISMIP3d intercomparison, J. Glaciol., 60, 353-360, https://doi.org/10.3189/2014JoG13J093, 2014.

Fretwell, P., Pritchard, H. D., Vaughan, D. G., Bamber, J. L., Barrand, N. E., Bell, R., Bianchi, C., Bingham, R. G., Blankenship, D. D., Casassa, G., Catania, G., Callens, D., Conway, H., Cook, A. J., Corr, H. F. J., Damaske, D., Damm, V., Ferraccioli, F., Forsberg, R., Fujita, S., Gim, Y., Gogineni, P., Griggs, 
J. A., Hindmarsh, R. C. A., Holmlund, P., Holt, J. W., Jacobel, R. W., Jenkins, A., Jokat, W., Jordan, T., King, E. C., Kohler, J., Krabill, W., Riger-Kusk, M., Langley, K. A., Leitchenkov, G., Leuschen, C., Luyendyk, B. P., Matsuoka, K., Mouginot, J., Nitsche, F. O., Nogi, Y., Nost, O. A., Popov, S. V., Rignot, E., Rippin, D. M., Rivera, A., Roberts, J., Ross, N., Siegert, M. J., Smith, A. M., Steinhage, D., Studinger, M., Sun, B., Tinto, B. K., Welch, B. C., Wilson, D., Young, D. A., Xiangbin, C., and Zirizzotti, A.: Bedmap2: improved ice bed, surface and thickness datasets for Antarctica, The Cryosphere, 7, 375-393, https://doi.org/10.5194/tc-7-375-2013, 2013.

Frieler, K., Clark, P. U., He, F., Buizert, C., Reese, R., Ligtenberg, S. R. M., van den Broeke, M. R., Winkelmann, R., and Levermann, A.: Consistent evidence of increasing Antarctic accumulation with warming, Nat. Clim. Change, 5, 348-352, 2015.

Fujita, S., Holmlund, P., Matsuoka, K., Enomoto, H., Fukui, K., Nakazawa, F., Sugiyama, S., and Surdyk, S.: Radar diagnosis of the subglacial conditions in Dronning Maud Land, East Antarctica, The Cryosphere, 6, 1203-1219, https://doi.org/10.5194/tc6-1203-2012, 2012.

Garbe, J., Albrecht, T., Levermann, A., Donges, J. F., and Winkelmann, R.: The hysteresis of the Antarctic Ice Sheet, Nature, 585, 538-544, https://doi.org/10.1038/s41586-020-2727-5, 2020.

Gladstone, R. M., Payne, A. J., and Cornford, S. L.: Parameterising the grounding line in flow-line ice sheet models, The Cryosphere, 4, 605-619, https://doi.org/10.5194/tc-4-605-2010, 2010.

Goelles, T., Grosfeld, K., and Lohmann, G.: Semi-Lagrangian transport of oxygen isotopes in polythermal ice sheets: implementation and first results, Geosci. Model Dev., 7, 1395-1408, https://doi.org/10.5194/gmd-7-1395-2014, 2014.

Goelzer, H., Nowicki, S., Payne, A., Larour, E., Seroussi, H., Lipscomb, W. H., Gregory, J., Abe-Ouchi, A., Shepherd, A., Simon, E., Agosta, C., Alexander, P., Aschwanden, A., Barthel, A., Calov, R., Chambers, C., Choi, Y., Cuzzone, J., Dumas, C., Edwards, T., Felikson, D., Fettweis, X., Golledge, N. R., Greve, R., Humbert, A., Huybrechts, P., Le clec'h, S., Lee, V., Leguy, G., Little, C., Lowry, D. P., Morlighem, M., Nias, I., Quiquet, A., Rückamp, M., Schlegel, N.-J., Slater, D. A., Smith, R. S., Straneo, F., Tarasov, L., van de Wal, R., and van den Broeke, M.: The future sea-level contribution of the Greenland ice sheet: a multimodel ensemble study of ISMIP6, The Cryosphere, 14, 30713096, https://doi.org/10.5194/tc-14-3071-2020, 2020.

Goldberg, D. N., Heimbach, P., Joughin, I., and Smith, B.: Committed retreat of Smith, Pope, and Kohler Glaciers over the next 30 years inferred by transient model calibration, The Cryosphere, 9 , 2429-2446, https://doi.org/10.5194/tc-9-2429-2015, 2015.

Hindmarsh, R. C. A., Vieli, G. J. M. C. L., and Parrenin, F.: A large-scale numerical model for computing isochrone geometry, Ann. Glaciol., 50, 130-140, https://doi.org/10.3189/172756409789097450, 2009.

Huybrechts, P., Rybak, O., Pattyn, F., Ruth, U., and Steinhage, D.: Ice thinning, upstream advection, and non-climatic biases for the upper $89 \%$ of the EDML ice core from a nested model of the Antarctic ice sheet, Clim. Past, 3, 577-589, https://doi.org/10.5194/cp-3-577-2007, 2007.

Joughin, I., Smith, B., Howat, I., and Scambos, T.: MEaSUREs Greenland Ice Sheet Velocity Map from InSAR Data, Version 2., Boulder, Colorado USA. NASA National Snow and Ice Data Center Distributed Active Archive Cen- ter, https://doi.org/10.5067/OC7B04ZM9G6Q, 2015 (updated 2018).

Jouvet, G., Röllin, S., Sahli, H., Corcho, J., Gnägi, L., Compagno, L., Sidler, D., Schwikowski, M., Bauder, A., and Funk, M.: Mapping the age of ice of Gauligletscher combining surface radionuclide contamination and ice flow modeling, The Cryosphere, 14, 4233-4251, https://doi.org/10.5194/tc-14-4233-2020, 2020.

Jouzel, J., Masson-Delmotte, V., Cattani, O., Dreyfus, G., Falourd, S., Hoffmann, G., Minster, B., Nouet, J., Barnola, J. M., Chappellaz, J., Fischer, H., Gallet, J. C., Johnsen, S., Leuenberger, M., Loulergue, L., Luethi, D., Oerter, H., Parrenin, F., Raisbeck, G., Raynaud, D., Schilt, A., Schwander, J., Selmo, E., Souchez, R., Spahni, R., Stauffer, B., Steffensen, J. P., Stenni, B., Stocker, T. F., Tison, J. L., Werner, M., and Wolff, E. W.: Orbital and millennial Antarctic climate variability over the past 800,000 years, Science, 317, 793-796, https://doi.org/10.1126/Science.1141038, 2007.

Karlsson, N. B., Bingham, R. G., Rippin, D. M., Hindmarsh, R. C., Corr, H. F., and Vaughan, D. G.: Constraining past accumulation in the central Pine Island Glacier basin, West Antarctica, using radio-echo sounding, J. Glaciol., 60, 553-562, https://doi.org/10.3189/2014JoG13J180, 2014.

Karlsson, N. B., Binder, T., Eagles, G., Helm, V., Pattyn, F., Van Liefferinge, B., and Eisen, O.: Glaciological characteristics in the Dome Fuji region and new assessment for "Oldest Ice", The Cryosphere, 12, 2413-2424, https://doi.org/10.5194/tc-12-24132018, 2018.

Konrad, H., Bohleber, P., Wagenbach, D., Vincent, C., and Eisen, O.: Determining the age distribution of Colle Gnifetti, Monte Rosa, Swiss Alps, by combining ice cores, ground-penetrating radar and a simple flow model, J. Glaciol., 59, 179-189, https://doi.org/10.3189/2013JoG12J072, 2013.

Lange, M. and van Sebille, E.: Parcels v0.9: prototyping a Lagrangian ocean analysis framework for the petascale age, Geosci. Model Dev., 10, 4175-4186, https://doi.org/10.5194/gmd-104175-2017, 2017.

Leysinger Vieli, G. J.-M. C., Hindmarsh, R. C. A., Siegert, M. J., and Bo, S.: Time-dependence of the spatial pattern of accumulation rate in East Antarctica deduced from isochronic radar layers using a 3-D numerical ice flow model, J. Geophys. Res.-Ea. Surf., 116, F02018, https://doi.org/10.1029/2010jf001785, 2011.

Lhomme, N., Clarke, G. K. C., and Marshall, S. J.: Tracer transport in the Greenland Ice Sheet: constraints on ice cores and glacial history, Quatern. Sci. Rev., 24, 173-194, https://doi.org/10.1016/J.Quascirev.2004.08.020, 2005a.

Lhomme, N., Clarke, G. K. C., and Ritz, C.: Global budget of water isotopes inferred from polar ice sheets, Geophys. Res. Lett., 32, https://doi.org/10.1029/2005g1023774, 2005b.

Lingle, C. S. and Clark, J. A.: A Numerical-Model of Interactions between a Marine Ice-Sheet and the Solid Earth - Application to a West Antarctic Ice Stream, J. Geophys. Res.-Oceans, 90, 11001114, https://doi.org/10.1029/JC090iC01p01100, 1985.

Locarnini, R. A., Mishonov, A. V., Baranova, O. K., Boyer, T. P., Zweng, M., Garcia, H. E., Reagan, J., Seidov, D., Weathers, K., Paver, C., and Smolyar, I.: World Ocean Atlas 2018, Volume 1: Temperature, NOAA Atlas NESDIS 81, 2019.

Martos, Y. M., Catalan, M., Jordan, T. A., Golynsky, A., Golynsky, D., Eagles, G., and Vaughan, D. G.: Heat Flux Distribution 
of Antarctica Unveiled, Geophys. Res. Lett., 44, 11417-11426, https://doi.org/10.1002/2017gl075609, 2017.

Morlighem, M., Williams, C. N., Rignot, E., An, L., Arndt, J. E., Bamber, J. L., Catania, G., Chauche, N., Dowdeswell, J. A., Dorschel, B., Fenty, I., Hogan, K., Howat, I., Hubbard, A., Jakobsson, M., Jordan, T. M., Kjeldsen, K. K., Millan, R., Mayer, L., Mouginot, J., Noel, B. P. Y., O'Cofaigh, C., Palmer, S., Rysgaard, S., Seroussi, H., Siegert, M. J., Slabon, P., Straneo, F., van den Broeke, M. R., Weinrebe, W., Wood, M., and Zinglersen, K. B.: BedMachine v3: Complete Bed Topography and Ocean Bathymetry Mapping of Greenland From Multibeam Echo Sounding Combined With Mass Conservation, Geophys. Res. Lett., 44, 11051-11061, https://doi.org/10.1002/2017gl074954, 2017.

Morlighem, M., Rignot, E., Binder, T., Blankenship, D., Drews, R., Eagles, G., Eisen, O., Ferraccioli, F., Forsberg, R., Fretwell, P., Goel, V., Greenbaum, J. S., Gudmundsson, H., Guo, J. X., Helm, V., Hofstede, C., Howat, I., Humbert, A., Jokat, W., Karlsson, N. B., Lee, W. S., Matsuoka, K., Millan, R., Mouginot, J., Paden, J., Pattyn, F., Roberts, J., Rosier, S., Ruppel, A., Seroussi, H., Smith, E. C., Steinhage, D., Sun, B., van den Broeke, M. R., van Ommen, T. D., van Wessem, M., and Young, D. A.: Deep glacial troughs and stabilizing ridges unveiled beneath the margins of the Antarctic ice sheet, Nat. Geosci., 13, 132-137, https://doi.org/10.1038/s41561-019-0510-8, 2020.

Mouginot, J., Scheuchl, B., and Rignot, E.: MEaSUREs Annual Antarctic Ice Velocity Maps 2005-2017, Version 1. NASA National Snow and Ice Data Center Distributed Active Archive Center, Boulder, Colorado, USA, https://doi.org/10.5067/9T4EPQXTJYW9, 2017.

Parrenin, F., Cavitte, M. G. P., Blankenship, D. D., Chappellaz, J., Fischer, H., Gagliardini, O., Masson-Delmotte, V., Passalacqua, O., Ritz, C., Roberts, J., Siegert, M. J., and Young, D. A.: Is there 1.5-million-year-old ice near Dome C, Antarctica?, The Cryosphere, 11, 2427-2437, https://doi.org/10.5194/tc-11-24272017, 2017.

Passalacqua, O., Ritz, C., Parrenin, F., Urbini, S., and Frezzotti, M.: Geothermal flux and basal melt rate in the Dome $\mathrm{C}$ region inferred from radar reflectivity and heat modelling, The Cryosphere, 11, 2231-2246, https://doi.org/10.5194/tc-11-22312017, 2017.

Passalacqua, O., Cavitte, M., Gagliardini, O., Gillet-Chaulet, F., Parrenin, F., Ritz, C., and Young, D.: Brief communication: Candidate sites of $1.5 \mathrm{Myr}$ old ice $37 \mathrm{~km}$ southwest of the Dome C summit, East Antarctica, The Cryosphere, 12, 2167-2174, https://doi.org/10.5194/tc-12-2167-2018, 2018.

Pattyn, F.: The paradigm shift in Antarctic ice sheet modelling, Nat. Commun., 9, 2728, https://doi.org/10.1038/s41467-018-05003$\mathrm{z}, 2018$.

feiffer, M. and Lohmann, G.: Greenland Ice Sheet influence on Last Interglacial climate: global sensitivity studies performed with an atmosphere-ocean general circulation model, Clim. Past, 12, 1313-1338, https://doi.org/10.5194/cp-12-1313-2016, 2016.

Purucker, M. E.: Geothermal heat flux data set based on low resolution observations collected by the CHAMP satellite be- tween 2000 and 2010, and produced from the MF-6 model following the technique described in Fox Maule et al. (2005), available at: https://core2.gsfc.nasa.gov/research/purucker/heatflux_ updates.html (last access: 4 August 2021), 2013.
Seroussi, H., Nowicki, S., Simon, E., Abe-Ouchi, A., Albrecht, T., Brondex, J., Cornford, S., Dumas, C., Gillet-Chaulet, F., Goelzer, H., Golledge, N. R., Gregory, J. M., Greve, R., Hoffman, M. J., Humbert, A., Huybrechts, P., Kleiner, T., Larour, E., Leguy, G., Lipscomb, W. H., Lowry, D., Mengel, M., Morlighem, M., Pattyn, F., Payne, A. J., Pollard, D., Price, S. F., Quiquet, A., Reerink, T. J., Reese, R., Rodehacke, C. B., Schlegel, N.-J., Shepherd, A., Sun, S., Sutter, J., Van Breedam, J., van de Wal, R. S. W., Winkelmann, R., and Zhang, T.: initMIP-Antarctica: an ice sheet model initialization experiment of ISMIP6, The Cryosphere, 13, 1441-1471, https://doi.org/10.5194/tc-13-14412019, 2019.

Seroussi, H., Nowicki, S., Payne, A. J., Goelzer, H., Lipscomb, W. H., Abe-Ouchi, A., Agosta, C., Albrecht, T., Asay-Davis, X., Barthel, A., Calov, R., Cullather, R., Dumas, C., Galton-Fenzi, B. K., Gladstone, R., Golledge, N. R., Gregory, J. M., Greve, R., Hattermann, T., Hoffman, M. J., Humbert, A., Huybrechts, P., Jourdain, N. C., Kleiner, T., Larour, E., Leguy, G. R., Lowry, D. P., Little, C. M., Morlighem, M., Pattyn, F., Pelle, T., Price, S. F., Quiquet, A., Reese, R., Schlegel, N.-J., Shepherd, A., Simon, E., Smith, R. S., Straneo, F., Sun, S., Trusel, L. D., Van Breedam, J., van de Wal, R. S. W., Winkelmann, R., Zhao, C., Zhang, T., and Zwinger, T.: ISMIP6 Antarctica: a multi-model ensemble of the Antarctic ice sheet evolution over the 21st century, The Cryosphere, 14, 3033-3070, https://doi.org/10.5194/tc14-3033-2020, 2020.

Shapiro, N. M. and Ritzwoller, M. H.: Inferring surface heat flux distributions guided by a global seismic model: particular application to Antarctica, Earth Planet. Sc. Lett., 223, 213-224, https://doi.org/10.1016/J.Epsl.2004.04.011, 2004.

Stal, T., Reading, A. M., Halpin, J. A., and Whittaker, J. M.: Antarctic Geothermal Heat Flow Model: Aq1, Geochem. Geophys. Geosy., 22, e2020GC009428 https://doi.org/10.1029/2020GC009428, 2021.

Stenni, B., Scarchilli, C., Masson-Delmotte, V., Schlosser, E., Ciardini, V., Dreossi, G., Grigioni, P., Bonazza, M., Cagnati, A., Karlicek, D., Risi, C., Udisti, R., and Valt, M.: Threeyear monitoring of stable isotopes of precipitation at Concordia Station, East Antarctica, The Cryosphere, 10, 2415-2428, https://doi.org/10.5194/tc-10-2415-2016, 2016.

Sutter, J., Fischer, H., Grosfeld, K., Karlsson, N. B., Kleiner, T., Van Liefferinge, B., and Eisen, O.: Modelling the Antarctic Ice Sheet across the mid-Pleistocene transition - implications for Oldest Ice, The Cryosphere, 13, 2023-2041, https://doi.org/10.5194/tc13-2023-2019, 2019.

Sutter, J., Eisen, O., Werner, M., Grosfeld, K., Kleiner, T., and Fischer, H.: Limited Retreat of the Wilkes Basin Ice Sheet During the Last Interglacial, Geophys. Res. Lett., 47, e2020GL088131, https://doi.org/10.1029/2020GL088131, 2020.

Talalay, P., Li, Y., Augustin, L., Clow, G. D., Hong, J., Lefebvre, E., Markov, A., Motoyama, H., and Ritz, C.: Geothermal heat flux from measured temperature profiles in deep ice boreholes in Antarctica, The Cryosphere, 14, 4021-4037, https://doi.org/10.5194/tc-14-4021-2020, 2020.

The PISM authors: Repository for the Parallel Ice Sheet Model (PISM), available at: https://github.com/pism/pism, last access: 4 August 2021.

van Wessem, J. M., Reijmer, C. H., Morlighem, M., Mouginot, J., Rignot, E., Medley, B., Joughin, I., Wouters, B., Depoorter, 
M. A., Bamber, J. L., Lenaerts, J. T. M., van de Berg, W. J., van den Broeke, M. R., and van Meijgaard, E.: Improved representation of East Antarctic surface mass balance in a regional atmospheric climate model, J. Glaciol., 60, 761-770, https://doi.org/10.3189/2014JoG14J051, 2014.

Veres, D., Bazin, L., Landais, A., Toyé Mahamadou Kele, H., Lemieux-Dudon, B., Parrenin, F., Martinerie, P., Blayo, E., Blunier, T., Capron, E., Chappellaz, J., Rasmussen, S. O., Severi, M., Svensson, A., Vinther, B., and Wolff, E. W.: The Antarctic ice core chronology (AICC2012): an optimized multi-parameter and multi-site dating approach for the last 120 thousand years, Clim. Past, 9, 1733-1748, https://doi.org/10.5194/cp-9-17332013, 2013.

Waddington, E. D., Neumann, T. A., Koutnik, M. R., Marshall, H. P., and Morse, D. L.: Inference of accumulation-rate patterns from deep layers in glacier and ice sheets, J. Glaciol., 53, 694712, https://doi.org/10.3189/002214307784409351, 2007.

Welker, C., Martius, O., Froidevaux, P., Reijmer, C. H., and Fischer, H.: A climatological analysis of high-precipitation events in Dronning Maud Land, Antarctica, and associated large-scale atmospheric conditions, J. Geophys. Res.-Atmos., 119, 11,93211,954, https://doi.org/10.1002/2014JD022259, 2014.
Winkelmann, R., Martin, M. A., Haseloff, M., Albrecht, T., Bueler, E., Khroulev, C., and Levermann, A.: The Potsdam Parallel Ice Sheet Model (PISM-PIK) - Part 1: Model description, The Cryosphere, 5, 715-726, https://doi.org/10.5194/tc-5-715-2011, 2011.

Winter, A., Steinhage, D., Arnold, E. J., Blankenship, D. D., Cavitte, M. G. P., Corr, H. F. J., Paden, J. D., Urbini, S., Young, D. A., and Eisen, O.: Comparison of measurements from different radio-echo sounding systems and synchronization with the ice core at Dome C, Antarctica, The Cryosphere, 11, 653-668, https://doi.org/10.5194/tc-11-653-2017, 2017.

Winter, A., Steinhage, D., Creyts, T. T., and Eisen, O.: Radio-echo sounding isochrone depths in the East Antarctic Ice Sheet, PANGAEA, https://doi.org/10.1594/PANGAEA.895528, 2018.

Winter, A., Steinhage, D., Creyts, T. T., Kleiner, T., and Eisen, O.: Age stratigraphy in the East Antarctic Ice Sheet inferred from radio-echo sounding horizons, Earth Syst. Sci. Data, 11, 10691081, https://doi.org/10.5194/essd-11-1069-2019, 2019.

Zwally, H. J., Giovinetto, M. B., Beckley, M. A., and Saba, J. L.: Antarctic and Greenland Drainage Systems, GSFC Cryospheric Sciences Laboratory, 2012. 